Comparative Philosophy Volume 13, No. 1 (2022): 21-57

Open Access / ISSN 2151-6014 / www.comparativephilosophy.org

https://doi.org/10.31979/2151-6014(2022).130105

\title{
THE YI-JING COSMIC MODEL AS A FRAMEWORK FOR COMPARATIVE PHILOSOPHY
}

\author{
HARRY DONKERS
}

\begin{abstract}
Based on the symbolism of the trigrams, the Yi-Jing cosmic model offers possibilities in a coordinate system with eight octants to discuss different philosophical developments in parallel. It forms a framework for further elaboration of theory and methodology of comparative philosophy. This paper is restricted to extracting, analyzing and comparing common features from the perspectives of the Yi-Jing model. Achieving harmony is the subject of a new paper under construction. The philosophical developments in the quadrants, Naturalism, Moralism, Rationalism and Humanism, are characterized by a fundamental difference between subject and object. This difference remains intact in the octants, but specified developments underline the subject and others the object. In Naturality man or woman does not consider him- or herself more valuable than other life forms, as in Daoism and ecocentrism. In Existentiality man or woman places his or her "ego" at the center and should give meaning from itself, as in existentialism. In Connectivity emphasis is on the human being, looking for liberation, as in Buddhism and parts of Hindu philosophy. In Normativity the subject focuses on the object, through norms and values, as in ancient China and Greek culture, and in modern technology assessment. In Rationality man or woman sees him or herself as more important. In Differentiality an anti-subject attitude arises, which led to phenomenology, hermeneutics, postmodernism and difference thinking. In Sociality, emphasis is on society and reality determines the idea. In Humanity emphasis is on the person, as in Confucianism, which strives for harmonious human relationships.
\end{abstract}

Keywords: Yi-Jing, Supreme Polarity, octant, cosmos, model, YI Ba-gua, levels, comparative philosophy

\section{INTRODUCTION}

The classic Confucian Book of Changes (the Yi-Jing) and the Diagram of Supreme Polarity by the neo-Confucianist Zhou Dunyi, inspired the creation of a cosmic model (Donkers 2020). It has been pointed out that the four quadrants of the coordinate system in this model, which correspond to the duograms of the Yi-Jing, provide opportunities

DONKERS, HARRY: Independent Scholar, the Netherlands. Email: hdonkers@ziggo.nl 
to discuss different philosophical traditions in parallel: naturalism, rationalism, humanism and moralism. In every tradition there is a fundamentally different attitude of the subject towards the object. There are similarities with Libbrecht's (2016) comparative model, but also differences. Libbrecht just distinguishes three perspectives. He considers naturalism and humanism as one category. The concept of energy is also different.

In the cosmic model, by adding diagonal axes to the coordinate system, eight octants have been obtained, which correspond to the trigrams of the Yi-Jing. This provides eight coherent and more diverse perspectives from which to view the world. It also offers opportunities for further differentiation of the different philosophical traditions. This is important because, unlike in the past, the philosophical landscape can no longer be clearly depicted in a quadrant system because there is now much more diversity. In general, we find that the attitude of the subject towards the object does not change fundamentally, but that the subject either the object becomes more important or receives more emphasis. The Yi-Jing cosmic model offers the opportunity to discuss different philosophical traditions in parallel. Philosophical considerations from both East and West are involved in each octant. This contributes to the theory and methodology of comparative philosophy, especially that part of comparative philosophy, which deals with cross-tradition engagement, by extracting, analyzing and comparing common features and differences. The other important part of comparative philosophy, namely achieving harmony (harmonious balance) is the subject of a new paper under construction.

Section 2 shows the diagram of Supreme Polarity and summarizes an elaboration of this Diagram with the introduction of trigrams. Section 3 discusses the Cosmic ring in a quadrant system and reviews the philosophical movements associated with these quadrants. Section 4 discusses the Cosmic Yi-Jing model in an octant system. It pays attention to the transition from quadrants to octants and shows which differentiated philosophical movements this leads to. In the quadrant naturalism we see a development with more emphasis on the object, such as in Naturality, and also a tendency where the subject starts to feel more important, leading to Existentiality. In the rationalism quadrant we see that this tradition develops further into Rationality with emphasis on the subject, but we also see a development in which the object becomes more important. That leads to Differentiality. In the humanism quadrant we see a further development towards Humanity, with more emphasis on the subject, and also a tendency, in which the object becomes more visible. That leads to Sociality. In the moralism quadrant we see that this tradition undergoes a further development into Connectivity, with more emphasis on the subject, and also a development with emphasis on the object. This leads to Normativity. Section 4 also provides an explanation of the $\mathrm{Yi}$ - Jing model as a framework for comparative philosophy. In section 5 we take a closer look at the model and discuss the eight philosophical movements associated with it in greater detail. 


\section{DIAGRAM OF SUPREME POLARITY}

The Yi-Jing philosophy means the philosophical dimension of the resources of thought delivered and suggested in the Yi-Jing 易經 (the Book of Changes, also called I Ching, ${ }^{1}$ ). The Yi-Jing text is understood in its classical or narrow sense and in its broad sense. In its classical sense it means the Zhou-Yi text that consists of the 64 ideographic symbols, the hexagrams, and their respective explanatory texts. In its broad sense it means the Yi-Jing text consists of the Yi-Jing text in its narrow sense and the subsequent commentary elaborations of the Zhou-Yi text, called the Ten Wings (i.e., the Yi-Zhuan), which are largely Confucian interpretative elaborations of the Zhou-Yi text (Mou, 2020). For Confucius, philosophy was a means of learning to become a person in the larger whole of the community. In the Book of Changes, the processes in the cosmos and in the human world are represented as the result of the interplay between Yin and Yang. The Yi-Jing has not only influenced Confucian thought but also neo-Confucian thinking. The neo-Confucianist Zhou Dunyi depicts with his Diagram of Supreme Polarity (Tai-Ji-Tu-Shuo 太極圖說) in a nutshell the evolution of the dynamic and selfgenerating cosmos or universe, shown in the left panel of figure 1. The right part of figure 1 shows an elaboration of the diagram of Zhou Dunyi by Donkers (2020). Graphically, both diagrams consist of 5 circles. The first circle indicates that the universe is an organic unit without beginning and end, symbolized by the void $(W u-j i)$. With the second circle, which is actually a picture of the Water and Fire trigrams, Zhou Dunyi depicts the changing aspects of Yin and Yang as a dynamic and bipolar complementarity. In our operation we symbolize the interaction between Yin and Yang through the original unity (Tai-ji), under the influence of the qualities of vital energy, $q i$, and pattern or form, $l i{ }^{2}$ In the left part of Figure 1 (Cheng 2009), the third circle consists of five smaller circles that symbolize the Five Phases. In the order of the socalled production cycle, these are: wood, fire, earth, metal and water. The Five Phases are a product of the interaction between Yin and Yang, symbolized by the V sign between the second and third circles. In our elaboration, the right part of Figure 1, we combine the Five Phases with the associated trigrams. The trigrams, capitalized, and the associated phases, in brackets, are these: Heaven (large metal), Wind (wood), Fire (fire), Mountain (earth), Lake (metal), Water (water) Thunder (wood) and Earth (great earth). The trigrams Heaven and Earth are seen in this context as instigator and recipient respectively of the production cycle. We show here that there is a successive process of recursive differentiation, via the twofold (Yin and Yang), the fourfold (duograms), to the eightfold (the trigrams combined with the Five Phases) The special thing here is that the order of the trigrams, from left to right, corresponds to the order of the Five Phases in the production cycle. In both diagrams of figure 1, a small empty circle symbolizes the connection between the third and fourth circles. The fourth and fifth circles are empty and focus on biological reproduction. The two circles indicate that

\footnotetext{
${ }^{1}$ Translation by Richard Wilhelm (Wilhelm, 2016).

${ }^{2}$ Taken from Hon (2010).
} 
the elusive forces of the cosmos manifest in the creation of the innumerable beings (the 10,000 things), i.e., the material world.
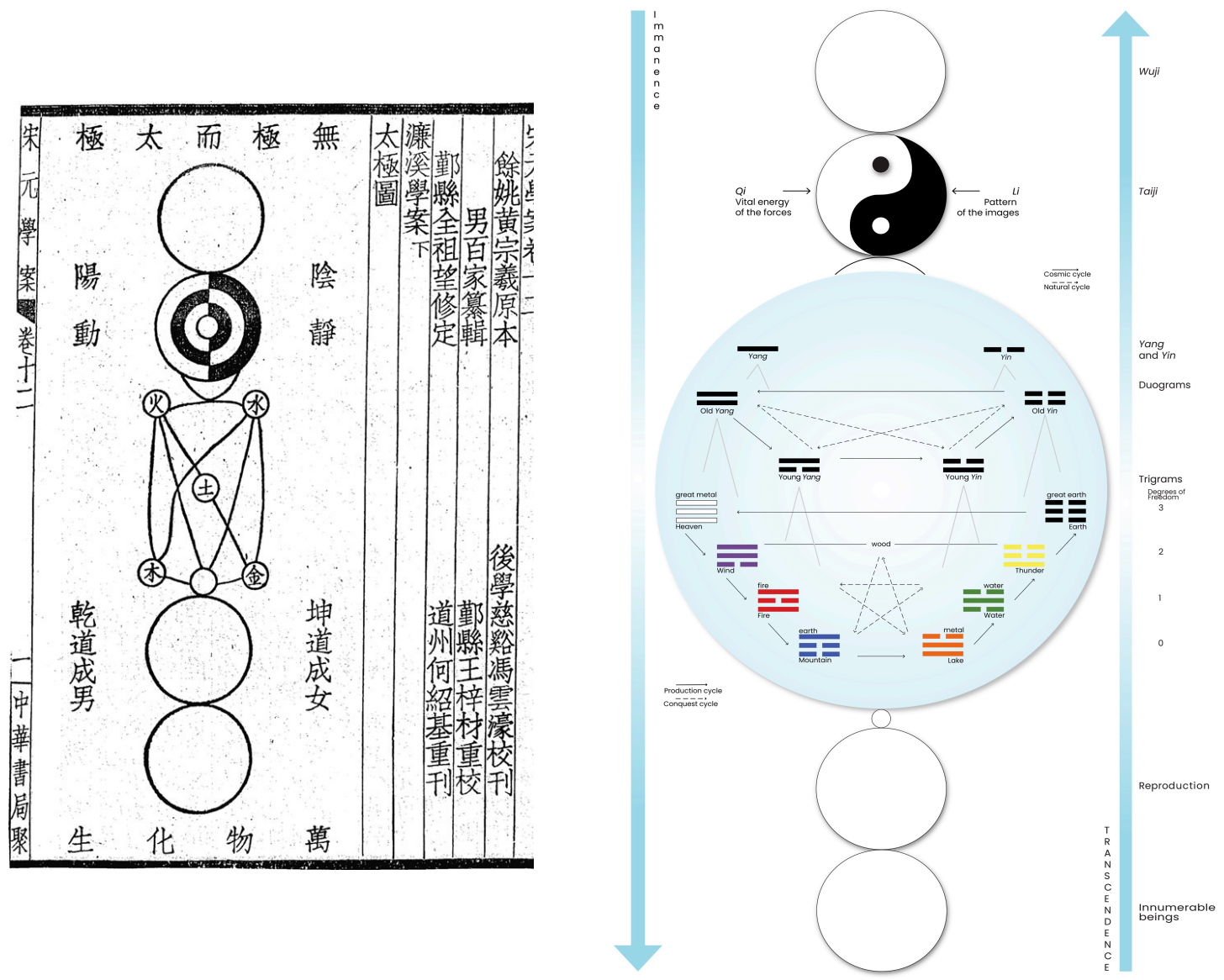

Figure 1. Diagram of the Supreme Polarity

Based on this diagram, Zhou Dunyi observes three important characteristics. First of all, the universe is not empty, but organic. Second, the universe and beings are interdependent as a part and as a whole. Third, the unfolding of the universe can be understood in two opposite directions: a step-by-step extension of the Supreme Polarity to the 10,000 things and a process of tracing the source of the 10,000 things back to the Supreme Polarity. In our presentation, in the right part of Figure 1, we describe this as a process of immanence and transcendence respectively. We point out that we also see this reflected in the sequence of the trigrams: with first decreasing degrees of freedom and, after a turning point, increasing degrees of freedom respectively. For example, in the order from Heaven, via Wind and Fire to Mountain, there is always a degree of freedom less and in the order from Lake, via Water and Thunder to Earth, a degree of freedom is added again and again. 


\section{COSMIC RING}

\subsection{COORDINATE SYSTEM}

We have seen that the interaction between Yin and Yang is symbolized by the original oneness (Tai-ji), influenced by the qualities of vital energy, qi, and pattern or form, $l i$. Every thing has two aspects: that which makes "how" a thing is is $l i$, and that which makes "that" it really is is qi. These are universal basic concepts, which we use to create a coordinate system, with energy on the horizontal axis and pattern or form on the vertical axis. The coordinate system allows for further analysis of the unfolding of the universe as a cyclical process.

We assume that the unfolding of the universe begins with free (chaos) energy and moves to a stage of bound energy, after which a process to free energy occurs again. We are supported in this by the thoughts of Young (1999), who describe the development of the universe in his "Reflexive Universe". He considers the development of the universe from the very beginning to the development of human consciousness. First, there is a process with decreasing degrees of freedom, from pure potency, via highly mobile particles and atoms to immobile molecules (involution). This is an immanent process of binding energy that leads to a bound energy state. The energy is always directed inward here. After that, a process with increasing degrees of freedom takes place, through the creation of plants, animals and eventually humans (evolution). This is a transcendent process of release of energy that leads to free energy that is directed outward. Young's model is a fractal model, which we can also apply to other levels, such as the development from the emergence of human consciousness to the end of time. In terms of the Yi-Jing, we can think of a process as described by the production cycle, with Heaven as the instigator and Earth as the receiver, where $q i$ causes these changes to take place. Thus, the polarities of energy on the horizontal axis of the coordinate system go from free energy directed inward through bound energy to free energy directed outward.

"How" the changes from Yang to Yin take place, so how things take shape, is the terrain of the pattern or form aspect of $l i$. Many different developments are possible. This development is directional, rather than directed. We refer to this orientation as intentionality. In the cosmos this intentionality is driven by Yang and Yin. In the human world, the focus is on the subject (ego-intentionality) or starting with the subject (alterintentionality). This touches on the relationship between the natural order and the moral order and thus enters the field of cosmology and ethics, which has played a role in the view of the world since Confucius (Adler 2015). Thus, the polarities of pattern/form on the vertical axis go from ego-intentionality to alter-intentionality.

\subsection{FOUR QUADRANTS}

We now place the duograms in a quadrant system with axes energy, derived from vital energy $q i$, and intentionality, derived from the pattern $l i$. The duograms consist of two 
lines, broken or open and continuous or closed. The bottom line is on the natural earth or body location and the top line is on the natural sky or spirit location. The axes divide the coordinate system into four quadrants, see figure 2. Four fundamental cosmological-anthropological perspectives arise:

- Old Yang: Ego intentional with energy turned inward $=>$ Naturalism

- Jong Yin: Ego intentional with energy directed outwards $=>$ Rationalism

- Old Yin: Alter-intentionality with energy directed outwards $=>$ Humanism

- Young Yang: Alter-intentionality with energy turned inward => Moralism

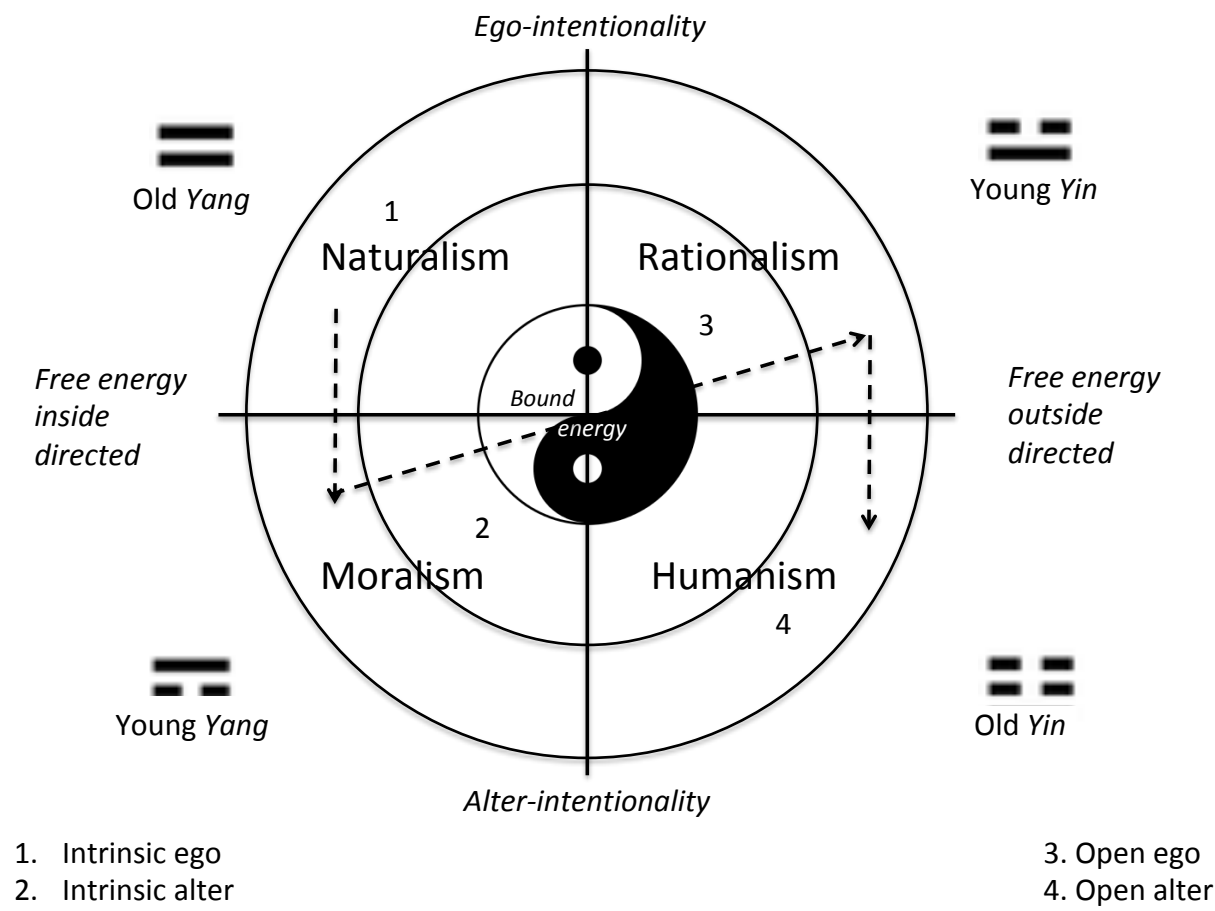

Figure 2. Cosmic ring

In figure 2 we can discover two cycles. Clockwise we see the natural cycle. For example, Old Yang is associated with summer, Young Yin with autumn, Old Yin with winter and Young Yang with spring. The spiral sequence shows the cosmic cycle as a process of change from Yang to Yin. Old Yang first turns into Young Yang, then into Young Yin, and finally into Old Yin. We use the classical Chinese representation for the duograms. ${ }^{3}$

\footnotetext{
${ }^{3}$ We note that in the translation of the Yi-Jing, Wilhelm has switched the names for Young Yin and Young Yang (Wilhelm 2016: 271).
} 


\section{a. Top left quadrant: Naturalism}

In the upper left quadrant, free energy is directed inward and ego-intentionality plays a role. This "intrinsic ego" force is active in the system, especially in the quadrant of the Old Yang duogram, but also radiates to the other quadrants. In figure 2 this is shown by the concentric circle (1). The lines of the Old Yang duogram are closed to heaven and to earth. Man or woman is busy with him- or herself. It's about inspirations and aspirations: making plans without disclosing them. He or she is completely absorbed in the world. There is no superhuman perspective. This is like in nature, where everything naturally becomes self-evident, like the continuous cyclical change (seasons, life and death). Human life is a process of "becoming". Man or woman is "in" nature. The subject (human) is part of the object (world) ( $\mathrm{S} \subset \mathrm{O}$ ). This is best expressed in Daoism, but it is also representative of other cultures that rely on nature for their survival (Aboriginal people, early agricultural cultures). In Daoism, mental and physical are indivisible and represent a non-dualistic way of looking at reality. The art of living in Daoism focuses on following our intuition, arranging according to nature, and finding harmony. The good life in Daoism is not to carry out a grand program or to achieve a goal, but to walk a "way". We call this quadrant: Naturalism, with Daoism as the main philosophical movement.

\section{b. Top right quadrant: Rationalism}

In the upper right quadrant, in addition to ego-intentionality, free energy that is directed outwards plays a role. This "open ego" force is active in the system, especially in the quadrant of the Young Yin duogram, but it also radiates to the other quadrants. This is represented by the concentric circle (3) in figure 2. The lines of the Young Yin duogram are open to heaven and closed to earth. Man or woman objectifies the world that is perceived and is performance-oriented. This rational function explains the world in logical schemes and thus tries to cut away subjectivity. Man places himself outside the world, as it were. The subject is opposite the object $(\mathrm{S}<->\mathrm{O})$. Here we strive for complete insight, as we see in the achievement-oriented pursuit of objectivity of science. Science is expected to provide solutions to all problems, as in scientism. This is the area of "being", with roots in Greek philosophy. There is a fundamental split between mental and physical phenomena. This dualism, which may involve a superhuman perspective, manifests itself, for example, in faith, such as the Abrahamic religions and some forms of Hinduism, or in the distinction between body and mind made in rationalism, which can be traced back to Plato and Aristotle. We call this quadrant: Rationalism, with scientism as the main philosophical trend.

\section{c. Lower right quadrant: Humanism}

In the lower right quadrant free energy is directed outwards and alter intentionality plays a role. This "open alter" force is active in the system, especially in the quadrant of the Old Yin duogram, but also has an effect on the other quadrants. In figure 2 this is represented by the concentric circle (4), in which the opposite force "intrinsic ego" is also active. The lines of the Young Yin duogram are open to heaven and to earth. Here man or woman focuses on the world. A humanistic world is obtained through 
education, learning and development of the moral character of people, as in Confucianism. The object (world) becomes, as it were, a product of the subject (human) ( $\mathrm{S}$ includes $\mathrm{O}$ ). Both in science and in practical experience, "learning/educating" and social harmony are important. There is one reality and nothing stands alone: there is non-dualism. We see similarities between Confucius and Socrates. Both wanted to ennoble and humanize the character of rulership in society, and cultivate the moral character of people through education and development, as Tan and Wong (2008) note. Reality then becomes a product of people. We call this quadrant: Humanism, with Confucianism as the main philosophical stream.

\section{d. Lower left quadrant: Moralism}

The lower left quadrant combines free energy directed inward with alter intentionality. This "intrinsic alter" force is active in the system, especially in the quadrant of the Young Yang duogram, but also radiates to the other quadrants. In figure 2 this is represented by the concentric circle (2), in which the opposite force "open ego" is also active. The lines of the Young Yang duogram are closed to heaven and open to earth. Man or woman does not place him- or herself outside the world, but the subjective experience of man or woman coincides with the opinions, norms and values that are shared within the cultural community. In other words, there is no longer any distinction between subject and object $(\mathrm{S}=\mathrm{O})$. This is the area of "non-being", comparable to pure experience or conceptual emptiness, the state of enlightenment in the philosophy of Buddhism. There is no distinction between material body and immaterial mind: monism. For example, Buddhism views all phenomena as non-real, illusory or empty. Also according to Spinoza (1979) there is only one substance and body and mind are aspects of it. Daniel Dennett (1991) also rejects Descartes' ideas about mind and body. We call this quadrant: Moralism, with Buddhism as the main philosophical direction.

The Cosmic ring is comparable to Libbrecht's model of comparative philosophy (2016), but there are also differences. Differences concern a different concept of energy. In Libbrecht's concept, energy is immanent in nature and transcendent only in humans. We believe that the unfolding of the universe begins with free energy directed inward and continues in an immanent process through bound energy and a transcendent process to free energy directed outward. Furthermore, Libbrecht regards naturalism and humanism as one category. We make a distinction between the absorption of man or woman into the environment and vice versa, the absorption of the environment into man or woman. The Cosmic ring is also comparable to the quadrant system of Wilber's Integral Theory (2004). The axes of Wilber's quadrant system, "inside" versus "outside" is in a sense comparable to "free energy directed inwards" versus "free energy directed outwards". And "ego -" versus "alter intentionality" is in a sense comparable to "I" versus "we". Wilber calls the upper left quadrant the 'intentional' quadrant. Because we use the term 'intentional' in a different sense, we can also speak here of 'aspirational'. For the upper right quadrant, Wilber uses the general term 'behavior'. We prefer to speak of the more specific term 'performance' quadrant. The terms that Wilber uses for the lower right and lower left quadrants, namely social and cultural respectively, also apply to the quadrants of the cosmic ring. 


\section{YI-JING COSMIC MODEL}

\subsection{DIAGONAL AXES AND OCTANTS}

The addition of diagonal axes creates more diversity in the system. We can then study the trigrams and associated philosophical movements in an octant system. These diagonal axes are based on the tension between competition and cooperation, and on the tension between renewal and preservation.

The first diagonal axis concerns the contrast between the quadrants Naturalism and Humanism. What one experiences from within in the Naturalism quadrant is internal consciousness. That is where the intentions, goals and values of the human being arise, which they strive for. The motive for this development is expressed in a competitive attitude. Competition often involves the struggle between different organisms or parties for scarce resources or to achieve a specific goal that by its nature is reserved for only a few. Darwin already observed this when he saw the emergence of species in nature as the sole consequence of competitive success of small variations. In the Humanism quadrant, parties will look together for solutions to deal in harmony with each other and with the limited resources. Cooperation is the driving force here. We also see a certain form of cooperation in the Naturalism quadrant. Because of his survival and reproduction, man or woman can manifest him- or herself altruistically, which then arises out of self-interest. The angles on this diagonal axis are therefore competition and cooperation.

The second diagonal axis concerns the contrast between the quadrants Rationalism and Moralism. The outward-facing world of individuals in the Rationalism quadrant is focused on knowledge, expression and growth, i.e., renewal. Society is constantly changing. In this way, new inventions are constantly being made, partly due to the rise of the natural sciences. In the Moralism quadrant, people look at what goes on within a collectivity. He or she sees him- or herself as a guardian of the norms and values within the community. For example, he or she will wonder whether new technological developments are all good for society. The perspectives on this diagonal axis are therefore renewal and preservation.

By introducing diagonal axes we have now obtained a system with eight octants. See figure 3. The locations of the trigrams in the Cosmic model follow directly from the duograms in the Cosmic ring, by always adding a Yang (continuous) line and a Yin (broken line) to the duograms in each quadrant from left to right on the middle place, which is the natural man or psyche place. Like the duograms, the trigrams are closed to heaven, seen from the perspective of inward energy, and open to heaven, seen from the perspective of outward energy. The trigrams in the direction of ego-intentionality are closed to the earth and in the direction of alter-intentionality they are open to the earth.

In the Diagram of Supreme Polarity we saw that the basis of cosmic development is the force $q i$, which supplies the cosmic energy so that the pattern $l i$ can realize the images. Cheng (2009) indicates that these are two sets of properties that exist side by 
side and cannot be separated, $q i$ has qualities such as change, transformation and movement and $l i$ has qualities such as patterns, forms and order, which can be recognized in the symbolism of the eight trigrams. We refer to the forms and patterns of the trigrams as "images", and the change and transformation as "forces". The images (forces) are known as: Heaven (inspiration), Wind (observing), Fire (thinking), Mountain (body), Lake (feeling), Water (soul), Thunder (spirit), and Earth (receptive). This has resulted in eight perspectives for looking at processes in the cosmos/world. The spiral sequence of the trigrams in the cosmic model in Figure 3 is a process sequence. As in the Diagram of Supreme Polarity, this sequence also corresponds here to the sequence of the Five Phases in the production cycle.

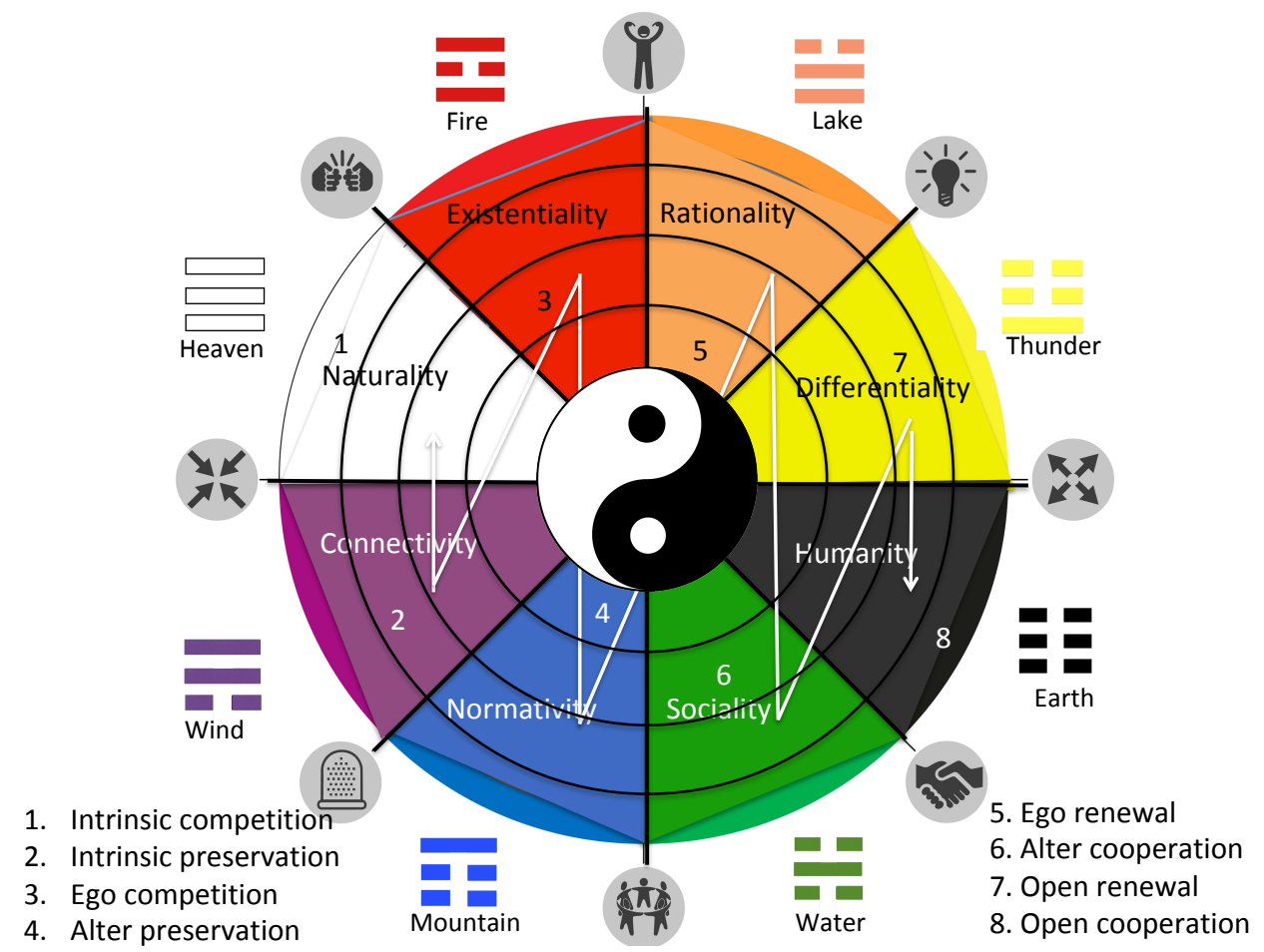

Figure 3. Cosmic model

Because the basis of this coordinate system lies in our elaboration of the diagram of the Supreme Polarity and the cosmic ring, and also interfaces with Wilber's Integral Theory, we call this arrangement of the trigrams $(\mathrm{Ba}-\mathrm{Gua})$ the 'cosmic Yi-Jing integral order', or the $Y \mathrm{I} B a-G u a$ 易八 for short. YI are initials of 'Yi-Jing' and 'Integral', and $Y i$ 易 means “change" in Chinese.

The clockwise sequence of the trigrams in the YI-Ba-Gua deviates from King Wen's Ba-Gua, the oldest known arrangement of trigrams, also called 'later celestial ordering', which has been used already for more than 2000 years, but there is a 
relationship between them. ${ }^{4}$ Compared to Fu Xi's "former celestial ordering", Ba-Gua, which has also been used for two thousand years, the Fire-Water and Lake-Mountain pairs have been interchanged. Compared to $\mathrm{Fu} X i$ 's $B a-G u a$, the $Y \mathrm{I}-B a-G u a$ has the advantage that when we take the spiral sequence in the coordinate system, it corresponds to the sequence of the Five Phases in the production cycle.

In the Cosmic model we have provided the trigrams with colors. In literature we come across the trigrams in different colors, which often lack a logical basis. We use a simple and logical reasoning here. Yang is always colored white and Yin is black; we leave this as it is. If we then start by giving the color red to Fire and we continue to choose the colors of the rainbow in a clockwise direction, the colors of the other trigrams will follow naturally. A green color for Water may be a bit surprising, but remember that Water and Fire are opposite to each other.

As we have seen, there is a relationship between the cosmic ring and Wilber's Integral Theory. Wilber's integral framework has been generalized to Spiral Dynamics by Donkers (2016). ${ }^{5}$ With this generalization, called "Integral Dynamics", Donkers (2019) simultaneously exposes the correspondence between the YI-Ba-Gua and Spiral Dynamics. "Integral Dynamics" differs from "Spiral Dynamics Integral" and also from an approach of Cacioppe and Edwards (2005), who sought the Holy Grail to integrate these models. While it is true that the colors of the Spiral Dynamics' categories would have been chosen randomly, with the exception of the first (Heaven) and the last (Earth) category, they do correspond to the colors that we have chosen above on a logical basis.

\subsection{FROM QUADRANTS TO OCTANTS}

The diagonal axes split each of the quadrants into two octants.

\section{a. Top left quadrant: Naturalism turns into Naturality and Existentiality}

In the upper left quadrant, the competition axis splits the quadrant (Old Yang) into two: "intrinsic competition", corresponding to the inspiration of the Heaven trigram, and "ego competition", corresponding to the thinking of the Fire trigram. Intrinsic competition is about forming new ideas to prepare for what's to come. This could be, for example, the preparation for a battle that is sometimes fought for survival. Even in less urgent cases, people will be inclined to choose, for example, "Me first" or they will try to be the first or the best. Ego competition is about the formation of skill or power, often at the expense of others, to stand strong or to achieve certain goals. This may, for example, involve acquiring as large a share as possible in the sale of goods and services, or gaining access to natural resources such as space, raw materials, energy sources, water, etc. Naturalism also splits into two movements along these lines. Within Naturalism we see on the one hand that the inward orientation of Daoism continues to develop over time from an original unity between man or woman and nature. We see

${ }^{4}$ This relationship is discussed by Donkers (2019).

${ }^{5}$ Spiral Dynamics is a model that describes consciousness development, on both a personal and collective level. It was originally developed by Graves (1970) and later popularized by Beck and Cowan (2006). 
more emphasis on nature. This is evident, for example, from the emerging ecocentric image of nature. This image emphasizes nature, whereby humans are not seen as more valuable than other forms of life, as described by Drenthen (2020). Due to this development, the emphasis shifts more towards the object and the "becoming-all". The subject is part of the object, but the object becomes more important $(\mathrm{S} \subset \underline{\mathbf{O}})$. This is the Naturality segment. Within Naturalism, on the other hand, we also see an anthropocentric or egocentric image of nature emerging, in which the ego is more central. Also according to Nietzsche (god is dead) man is not superior to nature. According to him, we need a widely recognized foundation that legitimizes our moral judgments, but there is none! This begs the question of whether a natural moral order exists without a superhuman perspective. This calls for attention to issues of meaning, as we see this within existentialism. There is then an emphasis on the subject and "becoming-self". The subject is part of the object, but the subject is more important ( $\underline{\mathbf{S}}$ $\subset \mathrm{O})$. This is the field of Existentiality.

\section{b. Top right quadrant: Rationalism, merges into Rationality and Differentiality}

In the upper right quadrant, the renewal axis splits the quadrant (Young Yin) in two: "ego renewal", corresponding to the feelings of the trigram Lake, which are uplifting, cheerful and positive in life, and "open renewal", corresponding the spirit of the Thunder trigram, which represents intense action. Ego renewal is all about enthusiasm, creativity and knowledge. Open renewal is about realizing things, together with other people, other organizations and other environments (co-creation), and innovating. Thus we see that Rationalism also splits up into two schools along these lines. On the one hand, rationalism continues to develop. Rationalism was already shaped in Western classical times and rationalism was also important in the Middle Ages, with knowledge strongly based on authority and revelation. René Descartes was the first to reduce his own existence from his thinking and not from the creation story. Everything could be approached rationally, with mathematics as an example. For example, Leibniz was convinced that if we only applied the mathematical method correctly, we could solve all problems, including political and social ones. Experience also comes into play with the rise of empiricism. Kant arrives at a synthesis: Knowledge comes about through a combination of reason and experience. Even in modern times, rationalism continues to develop and leads to scientific progress. The rational person thinks he is able to fully understand all events. The subject remains opposite to the object, but the subject becomes more important ( $\underline{\mathbf{S}}<=>0)$. This is about "being-self". We will discuss this in more detail in the theme Rationality. On the other hand, rationalism has been widely criticized. The criticism concerned the belief that only one truth, rationality and objectivity would be possible. According to phenomenology, the phenomena should speak for themselves. Postmodern philosophy questions the existence of an absolute truth: the free, reasonable man or woman does not exist. Identity issues and cultural minorities also receive more attention in late modern multi-ethnic societies through image formation and representation. There is more and more emphasis on "being-all". People are increasingly concerned with their environment, which is different everywhere. There is an anti-subject attitude in this movement. The object (the world, 
the environment) thus becomes more important $(\mathrm{S}<->\underline{\mathbf{O}})$. See the Differentiality segment.

\section{c. Lower right quadrant: Humanism merges into Humanity and Sociality}

In the lower right quadrant, the cooperation axis splits the quadrant (Old Yin) in two: "open cooperation", corresponding to the receptivity of the trigram Earth to properly land processes so that they can bear fruit in the future, and "alter cooperation", corresponding to the soul of the trigram Water, which moves with it to protect the collectivity from dangers. Open collaboration is about establishing connections between people, between organizations and between communities. In general, this concerns cooperation aimed at the outside world from a holistic approach. Alter cooperation focuses on forming partnerships in larger groups. We see that Humanism also splits into two schools along these lines. On the one hand, Confucianism, as the most important movement within Humanism, continues to develop. The philosophy of Confucianism was a means of learning to be a good person as part of society. ${ }^{6}$ The individual does not work for self-interest, but for the family and for the social environment. Experience (of rituals) was important. There is an emphasis on "learninghuman". Despite many disruptions, this development continues to date, with innovative initiatives over the last 30 years, whereby the role of the subject becomes more important: $\mathrm{O} \subset \underline{\mathbf{S}}$. See the segment Humanity. On the other hand, we see a more dialectical development within Humanism. In Socrates, dialectic was the method of achieving humanity in society. Over time, there have been many developments that build on this. For example, dialectics is used as a research method in critical science. We see developments in this that refer more to the collective, to society. There is an emphasis on "learning-society". The object (society) is considered more important in that development than the subject (the person): $(\underline{\mathbf{O}} \subset \mathrm{S})$. The Sociality segment is concerned with the collective and elaborates on this in more detail.

\section{d. Lower left quadrant: Moralism turns into Normativity and Connectivity}

In the lower left quadrant, the preservation axis splits the quadrant (Young Yang) in two: "Intrinsic preservation", corresponding to the feelings of the trigram Wind, which takes small steps with gentle and penetrating forces, without malice, and "alter preservation", corresponding to the body of the Mountain trigram, which represents tranquility and stability. Intrinsic preservation is about ensuring favorable and stable conditions in one's own living environment. Alter preservation is about usages, social norms and laws within cultures. We see that Moralism also splits into two schools along these lines. On the one hand, Buddhism, as the most important movement within Moralism, continues to develop. According to Buddha, there is no mind that is independent of the body. In Buddhism detachment is central, it develops further and focuses more inward. Dijkstra (2004), referring to Bor and Van der Leeuw (2003), talks about the way of internalization. We must not focus our desire on something from the outside world, because if we get it our problems will not be solved. There is an

\footnotetext{
${ }^{6}$ This is described, among others, by James and Bretzke (1995) and by Tazelaar (2012).
} 
emphasis on the subject and "non-being-self": $(\underline{\mathbf{S}}=\mathrm{O})$. We will discuss this in more detail in the Connectivity segment. On the other hand, norms and values come into the picture. In ancient China, the Mohists, and later the Legalists, sought a consistent system of ethics with objective moral standards, and without ritual. Concrete rules and laws would provide standards for judgment. The legalists held the premise that social bonds are less about people, but more about laws and sanctions that serve as external tools to maintain order. This was the beginning of a philosophy that focuses more on society as a collectivity from the point of view of a morally endorsed ideal or morality. Because this involves rules and norms of conduct we speak of moral normativity. See the Normativity segment, which is concerned with this philosophical movement. There is an emphasis on "non-being-all". The subject is equal to the object, but the object is more important $(\mathrm{S}=\underline{\mathbf{O}})$. See the Normativity segment.

\subsection{YI-JING COSMIC MODEL AS A FRAMEWORK FOR COMPARATIVE PHILOSOPHY}

In short comparative philosophy is occupied with A. cross-tradition engagement, by extracting, analyzing and comparing common features and differences and $\mathrm{B}$. achieving harmony of philosophies (Mou 2020).

\section{Sub A. Common features and differences}

Different viewpoints or perspectives are elaborated as Yang and Yin polarities. Through the successive process of recursive differentiation, the polarities are further differentiated and well expressed in the opposing quadrants of the quadrant system (cosmic ring) and in the opposing octants of the octant system (cosmic Yi-Jing model). In the quadrant system the philosophical main traditions are characterized by a fundamental difference in the ratio of subject to object as we saw in Donkers (2020). In the Yi-Jing model we can look at polarities in a more differentiated way than in the quadrant system, among others. Now it is possible to look at the polarities from eight different perspectives instead of four, or just three as Libbrecht (2016) does. These perspectives are universal. They imply that different philosophies are involved and compared, which make a more detailed analysis of cross-tradition engagement possible. In the octant system the fundamental relationships of the quadrant system remain intact, but in the octants we make a distinction between developments with an emphasis on the subject or the object. In the different philosophical movements we look at the various philosophical trends and developments from western and eastern points of view, always focused on the fundamental perspective of the polarity. This general way of doing philosophy is a central concern of comparative philosophy.

\section{Sub B. Achieving harmony}

In the octant system, the eight philosophical movements oppose each other in pairs, thus forming four contraries. Achieving harmony is related to the question how to look at contraries between the perspectives or polarities. Two ways of how to look at contraries are mentioned in literature: harmony in the Yin-Yang model and synthesis in 
the Hegelian model. These two models can jointly contribute to our understanding and treatment of the reflective issue of how to look at the due relation between contraries or conflicting parties. Both emphasize balance; the Yin-Yang way endeavors to reach harmony, while the Hegelian way endeavors to reach synthesis beyond thesis-antithesis through sublation.

Mou (2020) develops the notion of "Overall complementarity", which means an inclusive, pluralist notion of complementarity that is to cover distinct types of complementarity in an inclusively disjunctive way. He distinguishes two different complementarities: concordant and contradictory.

- Concordant-complementarity-seeking activities between concordant contraries may lead to harmonious balance. These are crucial features of the Yi-Jing methodological model. The Yin-Yang model emphasizes seeking and maintaining concordant complementarity and thus harmonious balance, but it does not deny the existence of contradiction and does not reject other types of complementarity.

- Restrictive-complementarity-seeking activities between contradictory contraries may lead to restrictive balance. This is addressed in the Hegelian model. Hegel conceives the world in terms of a contradictory progressive movement of Mind or Spirit toward full self-realization as self-conscious awareness (process of Mind). The process of Mind is not linear, but dialectical (thesis, antithesis and synthesis). Any given thesis intrinsically involves some internal contradictions that will generate an antithesis. Interaction and confrontation between thesis and antithesis lead to contradictions, thus bringing about the synthesis, previous contradictions are solved by "sublation". The synthesis will again be subject to further dialectics. The process repeats itself.

Mou (2020) presents a set of general "adequacy" conditions for how to adequately bridge contraries, in the form of "schema":

1. Concordant (or harmonious)-complementary-seeking condition between (seemingly competing) contraries within their unity;

2. Restrictive-complementary-seeking condition between contradictory contraries within their unity (pre-sublation);

3. Post-sublation complementary-seeking condition between contradictory contraries within their unity;

4. Excessiveness-overcoming condition (overcoming what is excessive and supplementing what is insufficient in the development of contraries within their unity, and having them in constructive and balanced development).

When contraries meet the excessiveness-overcoming condition it is possible to capture and maintain complementarity between these contraries by overcoming what is excessive and supplementing what is insufficient (schema 4). In this case one or both polarities are too extreme. This leads to risks. These risks have first to be solved before 
we can think about harmonious balances. When the polarity that is too extreme or too high is overcome or restricted and/or the polarity that is insufficient or too low is supplemented or improved, harmonious balance is possible. In case of the concordantcomplementary-seeking condition (schema 1), harmonious balance is possible between concordant contraries. This is the area that Wilhelm (2016) calls the 'Radius of Action' (in the Yi-Jing system this is the domain of the 64 hexagrams representing changing patterns of our environmental nature: the actual natural world in the process of change). It is a zone of viability. Here are also similarities with parts of organization theory, especially the category viability part (Lo et al, 2020). Between contradictory contraries only restrictive balance is possible. There are two opportunities. The contradictory contraries are mutually supportive and supplementary or they are not mutually supportive and supplementary. In case the contradictory contraries are mutually supportive (schema 2) in my opinion the route towards harmony should go via schema 4. In case the contradictory contraries are not mutually supportive (schema 3 ) they need their sublation. As far as the result of the sublation is concerned again two possibilities arise. After sublation, concordant complementarity may or may not be achieved. When concordant complementarity is reached after sublation harmonious balance comes into the picture. In the case concordant complementary is not reached after sublation, the contraries again need sublation.

In this way the Yi-Jing cosmic model and the Hegelian model can jointly contribute to our understanding and treatment of the reflexive issue of how to look at common features and differences and how to look at the due relation between contraries. Since extracting, analyzing and comparing common features takes place from the perspectives of the Yi-Jing cosmic model, and achieving harmony (harmonious balance) is only achieved through concordant contraries as in the Yi-Jing system, whether or not through intervention of the Hegelian model or otherwise, I conclude that the Yi-Jing cosmic model can be seen as a framework for comparative philosophy.

The purpose of this paper is restricted to highlight common features and differences of western and eastern philosophies from the eight perspectives in the Yi-Jing cosmic model (Sub A).

It is not the purpose of this paper to analyze contraries with the aim to build a vital world through seeking harmony. An impetus of such a model has been given in Donkers (2020), where eight trigrams are put opposite to each other, forming four contrasts or contraries as follows:

- Balancing ultimate polarities, between Heaven and Earth;

- Cultural relativism, between Wind and Thunder;

- Reciprocal solidarity, between Fire and Water;

- Creative moderation, between Mountain and Lake.

This model is not a philosophical inquiry but an application at society level, where only attention is paid to concordant contraries (schema 1), without paying explicit attention to the other adequacy conditions mentioned above (schema 2, 3 and 4). The application about an alternative to neoliberalism is just a limited approach, assuming that between 
concordant contraries harmonious balance could be achieved by finding fundamental values through balancing ultimate polarities resulting in core values, by developing fundamental objectives through cultural relativism producing a vision, by establishing fundamental purposes through reciprocal solidarity determining a mission and by constituting fundamental operations conducting a strategy.

A next step in the research could be to further explore the contraries between the different philosophical movements, taking into account all four adequacy conditions mentioned above, including excess and deficiency of either Yin or Yang. In terms of method, the organizational theory of category viability is of additional value, for example the work of Lo et al (2020). This, however, is the subject of a new paper under construction (Sub B).

In the Book of Changes, the processes in the cosmos and in the human world are represented as the result of the interplay between Yin and Yang. Yin and Yang are the two most basic and mutually opposed, but interdependent, interpenetrating and complementary forces which coexist in everything of the universe (this natural world) in various and distinct ways insofar as each of particular things has its own distinct identity (Mou 2020). This implies that everything in the universe can be considered from these two perspectives. Through a successive process of recursive differentiation from the twofold of Yin and Yang, arise the fourfold of the duograms and the eightfold of the trigrams. This means that the characteristic features of the trigrams (and also the duograms) are related to the two fundamental processes or properties in the universe. This implies that everything in the universe can be considered from these eight perspectives. Elaborating on this we can say that all philosophical movements can be classified into eight categories. This eightfold gives a more differentiated picture than the twofold (or fourfold). In the Yi-Jing, change is a fundamental aspect. There is no question of simple linear or vertical progress. The change model is that of a circle or a spiral, in which different points of view successively replace each other. In the octant system of the Yi-Jing cosmic model (and also in the quadrant system of the cosmic ring) we recognize both the circle and the spiral. How to fit the philosophical movements into the octants is studied in the part of comparative philosophy that deals with extracting, analyzing and comparing common features and differences of philosophies, which is the subject of this paper and is discussed in the next section.

\section{EIGHT PHILOSOPHICAL MOVEMENTS}

By moving from quadrants to octants we get more differentiation in the philosophical playing field. We saw earlier that the four quadrants are characterized by a fundamental difference in the ratio of the subject to the object. These fundamental relationships remain intact, but on the one hand we see philosophical developments that place more weight on the subject and, on the other hand, philosophical developments that emphasize the object. These shifts have consequences for the ontological orders. This leads to eight separate and very different philosophical schools. Based on the four philosophical main trends in the quadrants, we make a distinction between 
developments with an emphasis on the subject or on the object (anti-subject). Figure 4 provides an overview.

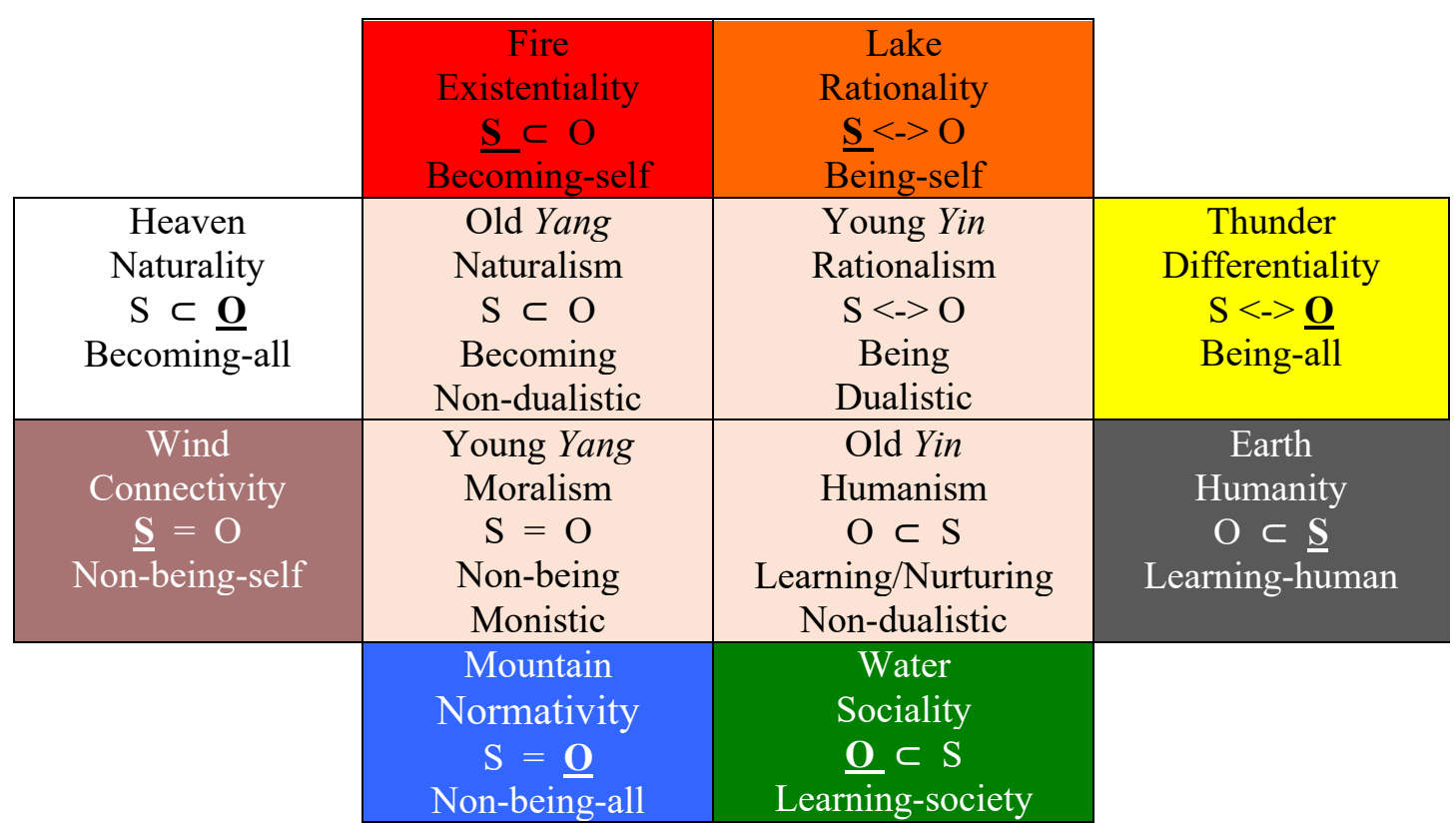

Figure 4. Diversification of philosophical movements

We see that in philosophical movements the relationships between subject and object are of great importance. Also in ontology and epistemology questions about knowledge are approached from the subject or from the object. In addition, thinking about knowledge in general is based on a certain model, which start from a dualistic concept, that is to say a separation between consciousness (subject) and world (object), or an integral concept. With an integral concept there is no separation between consciousness and the world. Then subject and object can be equal to each other (monistic) but they can also be part of each other (non-dualistic). In either case, the subject can determine the object to a greater or lesser extent or, conversely, the object can determine the subject to a greater or lesser extent.

The explicit inclusion of free energy in the model also leaves room for spirituality, religion, meaning and rituals. We will of course go into this in more detail when discussing the individual philosophical movements, but because of their importance, we will give a brief overview here. Spirituality is an attitude to life focused on the spiritual. Meditation is a form of practice of spirituality. Spirituality and meditation are transcendent developments that require free energy directed either inward or outward. We find this only at the extremes of the horizontal (energy) axis of the Cosmic model. In a transcendent development in Naturality and Connectivity, the energy is directed inwards. Spirituality and meditation are also directed inward here. With Naturality it is aimed at being one with nature, as in Taoism, and with Connectivity it is aimed at feeling connected with the cosmos, as in Buddhism. Also in Differentiality and 
Humanity there can be a transcendent development, but here the energy is directed outwards. Spirituality and meditation are also directed outwards here, resp. focused on living together consciously and responsibly, as in Hindu yoga, and feeling connected to each other, as in Confucianism. In Existentiality and Rationality the energy is more bound. In Existentiality, meaning, i.e. the search for meaning or value in life, plays a role. Meaning arises through personal reflection on basic experiences and in dialogue with someone else or others. A supernatural perspective can play a role in Rationality, such as the belief in $\operatorname{god}(\mathrm{s})$, or religion. Prayer and sacrifice are ways to practice religiosity. In Normativity and Sociality, with more bound energy, spirituality and meditation play a less important role. With regard to rituals, we point out the following. Rituals are appropriate ways of responding to matters of fundamental importance in life. Rituals are ubiquitous; they play a role everywhere to a greater or lesser extent.

In this section we will take a closer look at the eight philosophical trends we have derived from the Yi-Jing Cosmic Model. In the discussion we choose the spiral sequence.

\subsection{NATURALITY}

Naturality is the philosophical movement, in which the subject (man or woman) is part of the object (nature), with emphasis on the object and the "becoming-all". People are seen as manifestations of the natural processes in the world, as in Daoism. Daoism is described in the books of Lao Zi (2015) and Zhuang Zi (2011). Both books are composite texts with inputs from multiple anonymous writers. The Chinese word Dao (道) means a way or a path. By Daoists it is understood as the "Way of Nature" as a whole. Nature has lessons to offer about time and change, gain and loss, the useful and the useless. Human life is only a small part of a larger process of nature. Human actions that make sense are those, which are in accord with the flow of nature. How human beings should behave is expressed in the Dao-De-Jing as Wu-Wei (無為) or non-action. This means doing nothing unnatural and if one does something, it must be in harmony with nature. Related to non-action was the idea of no desires, which meant that no one should have excessive desires because such desires are bound to cause injury both to oneself and to others.

Important Daoist principles are that life is always in motion between the visible and invisible opposites of life: Yin and Yang. Life is seen as a cyclical process in contrast to Western linear thinking. Change is also a concept of the early Western philosopher Heraclitus (around $540 \mathrm{BC}$ ), who sees change as the cornerstone of reality, as a continuous, smooth change and cycle of things, called by Plato panta rhei (everything flows) (Herakleitos 2014).

According to the Daoists, man or woman does not have an anthropocentric mind, but is part of nature. Virtues belong to human nature. If we do not give it the chance, we see the greedy and warlike man. Lao-Tse denounced the injustice in the world, in which the rich are getting richer and the poor are getting poorer! Man's or woman's moral task is to return to the naturality of the Dao. Therefore, one focuses on simplicity, embraces the natural, diminishes selfishness and curbs desires. This can be achieved 
through inaction, not being attached to non-essential things like property and status, but to the satisfaction of needs. The central concept in this context is $W u$-Wei, the attitude of idleness.

Friedrich Nietzsche, influenced by Arthur Schopenhauer, was also involved in Eastern philosophy. He opposed rationalist and Western thinking. His work is closely related to Daoism. Both want to free nature from violent human distortions of nature. Nature also had a great influence on Immanuel Kant. Knowledge arises from perception and thinking. The observations are interpreted by patterns (categories). Also in the ecocentric image of nature there is an original unity between man or woman and nature, nature provides the standard. Man or woman is not seen as more valuable than other life forms. Daoism evolved over time in response to changing times, revising and refining its doctrine and associated practices. Recently, Daoism has emerged from a period of oppression and is undergoing a revival. Daoism is currently a vibrant philosophical system and way of life, as evidenced by the resurgence of practice and study in several new university institutions in China.

The purpose of spirituality in Daoism is to find inner peace and harmonize with the Dao through generation, transformation, and diffusion of the inner energy. The teachings of Lao-Tse emphasize the importance of meditation and nonviolence as means of attaining higher levels of existence. Some concepts of Daoism have also found expressions in the modern West, such as meditation through breath work, postures, and movements aimed at improving health and achieving longevity.

\subsection{CONNECTIVITY}

Connectivity is the philosophical movement, in which the subject (the human being) coincides with the object (the world), with an emphasis on the subject and "non-beingself". The monistic doctrine of the no-self is a central doctrine of Buddhism. Buddhism, with mainstream Theravada and Mahayana Buddhism, started with the ideas of Gautama Buddha and has a number of basic ideas (Quik 2008). The Dharma, the teachings of Buddha, includes the four noble truths and the eightfold path. By being liberated from the bondage of this world, greed, aversion and delusions will die out and one can attain nirvana, a state of perfect rest, freedom and supreme happiness. Also in ancient Hindu philosophy, which is otherwise largely dualistic, we encounter monism, especially in Advaita Vedanta (Veeraiah 2015).

Western philosophy is also increasingly open to a way of thinking that no longer has a purely dualistic worldview, as we have already seen with Parmenides. Baruch Spinoza and Buddhism have many similarities (Kuis 2015). According to Spinoza (1979) there is only one substance, and body and mind are aspects of it. The god in his expression "God is nature" (Deus sive Natura) is not a personal god but a substance with its own necessary and unchangeable laws. Schopenhauer had a strong interest in the Upanishads and Buddhism. Hegel (2013) aimed to develop a single total concept, in which reality is not seen as static, but as the result of a continuous, dialectical process, originally from Kant. Kant has a great interest in spirituality and mysticism, but how things really are we can never discover with our mind. There was a common ground 
with Martin Heidegger (2009), who had placed the concept of "Nichts" at the center of his "Sein und Zeit". Heidegger's philosophy connects well with the ideas of Zen Buddhism, which arose in the seventh century: enlightenment can be realized through meditation and introspection. Nietzsche was also interested in Eastern philosophy. Brobjer (2004) and Lathouwers et al (2010) show that there are similarities between Søren Kierkegaard's views and Zen Buddhism. Man or woman is spirit according to Kierkegaard, a relationship that relates to itself. No human being lives without being more or less desperate (unrest, disharmony, fear). The one who voluntarily gives up his freedom and is "empty" is open to the divine at any moment and can become "full" of and with god. This letting go of his anchoring in his individuality is like "emptying" in Buddhism. In Buddhism it is about something like an unknowable source, through which you are moved deep into your heart. If the possibility of freedom is respected, it will lead to salvation. Some insights of Freud also correspond with those of Buddha. According to both Buddha and Freud, desire manifested itself as the motor behind consciousness of man or woman and his or her desire for eternal life. By becoming acquainted with European thinkers, a Japanese Buddhist philosophy was able to develop in the Kyoto School, which sought a synthesis between traditional thinking and Western philosophy, especially that of Heidegger.

Spirituality in Buddhism aims to resolve human suffering by attaining a state of enlightenment. Important obstructing forces, such as lack of inner discipline, laziness, and obstructing emotions, can be removed by meditation. According to Buddha, the practice of mindfulness (sati), part of the eightfold path, is a direct way to liberation from patterns of discomfort and suffering and to awakening. In Theravada Buddhism, meditation is an essential part of the path to enlightenment, along with moral conduct and wisdom. Mahayana Buddhism focuses on the teachings of selflessness and emptiness, from the Middle Way through the yoga/meditation path to Zen. The Vedanta School of Hinduism has four yogic paths to union with the Supreme. These paths, which can also be found in (Zen) Buddhism, lead to the insight that we no longer see ourselves as an entity in a world of entities but as the consciousness in which the whole shows itself again and again as "this moment like it is". In the West, Jon Kabat-Zinn is developing Buddhist spirituality, including mindfulness, and Zen is becoming increasingly popular. However, it is often stripped of its Buddhist context and limited to physical and mental relaxation or goals related to career, relationships, etc. In the west, transcendental meditation (TM), with origins in the Vedic civilization, is a wellknown form of meditation, introduced in the late 20th century by Maharishi Mahesh Yogi. It would have effects on stress, PTSD, burnout, depression, insomnia, anxiety disorders, blood pressure, etc.

\subsection{EXISTENTIALITY}

Existentiality is the philosophical movement, in which the subject (man or woman) is part of the object (nature/world), with emphasis is on the subject and "becoming-self". Morality is not seen as something that rises above nature, but man or woman does consider him- or herself more valuable than other life forms. According to Socrates, 
man or woman has always been in search of the "self". To become a moral person, man or woman must first know him- or herself. We get "self-awareness" by debating with others, according to Socrates. Living a life as it is meant for human beings, that was how Aristotle thought we could achieve the good. Such a life is a virtuous life. We have to pick up the good character traits, which are innate with us. Furthermore, we must develop them by putting them into practice. Then they enable people to fulfil their tasks optimally.

An important question from Kierkegaard was "How does man or woman become him- or herself?" According to Kierkegaard, man or woman is only really him- or herself when he or she is an "individual". The individual is the unique individual who is constantly active in becoming an authentic self. Kierkegaard points out that meaning arises in concrete existence, not in an objective system. That is why many see him as the founder of existentialism. It is about the freedom of the individual. Kierkegaard was deeply impressed by nature and, according to him, man has the possibility of authenticity through freedom. In that nature, Kierkegaard came to one of the central concepts in his thinking, namely the fear of the complete meaninglessness of life. The core of our existence is an insoluble contradiction at the intersection of contingency and freedom. Kierkegaard believes that faith is the only way to relieve the pain that this causes. According to Kierkegaard, who was highly critical of established clergy and the corrupting workings of the church, true Christianity is the faith of love and forgiveness. His religious message was pushed aside by the atheistic existentialism (Dondeyne 1951) of Nietzsche, Jean-Paul Sartre, Ludwig Wittgenstein, Heidegger, Hannah Arendt and Jacques Derrida, among others.

According to Nietzsche (2006), we should not only give up belief in god (god is dead), but all belief in objective and absolute moral values. According to Nietzsche, this means that there is no morality, only a power struggle between people. All traditional grip will be lost and that could lead to an apocalypse, but strong "free" spirits are free to create their life-affirming values and an exciting new world will open up. All life forms - including humans - are driven by the "will to power", a fundamental driving force, an "inexhaustible reproductive will of life" in all things. Kant said that our cognitive abilities are limited. Kant's "Thing in itself" corresponds to Nietzsche's "will to power", characterized by suffering. In the unity of man or woman and nature, opposing forces are also active that play a role in the problem of meaning: Apollonian and Dionysian forces. The current problem is to find a balance or the right relationship between these forces. So we have to break through the desire for structure and the setting of boundaries.

Sartre's (1943) existentialism developed in line with the philosophical ideas of Kierkegaard and Nietzsche. Man or woman is condemned - by his consciousness - to absolute freedom, separate from everything and everyone, and is fully responsible for his or her actions. That can be scary, but it can also make you feel optimistic. Fear offers perspective on freedom. But man or woman cannot do that on his or her own. For Kierkegaard, god or faith came into the picture. According to Sartre, people themselves should give meaning to life through activities and choices. There is no god and there are no transcendent values that stand in the way of human freedom. Modern 
philosophy focuses on individual freedom. Identity and self-determination receive more attention. This saddles people with the responsibility of giving meaning themselves, which is difficult and often also frightening. The human who pursues hedonism develops a selfish mind. Erich Fromm (2007) points in this connection to the era of gaining money, greed and blind consumerism. The problem of meaning also offers an opportunity to discover values yourself, which provide energy for life. In this way Martha Nussbaum defines individual core capacities (capabilities) that make it possible to lead a meaningful life. ${ }^{7}$

\subsection{NORMATIVITY}

Normativity is the philosophical movement, in which the subject (man or woman) coincides with the object (the world), with emphasis on the object and on "non-beingall". Ethics is the science that studies morality. Morality is the entirety of shared moral views/judgments of a group of people that arise in conversations. Moral judgments concern the trade-off between different moral norms (self-imposed rules that prescribe behavior for good living together) and moral values (ideals or principles about good living together that we try to realize through behavior) in specific situations (Van Dalen 2012). Ethics and morality thus tries to establish criteria for judging whether an action can be judged right or wrong. Ethics plays a major role in every philosophical movement. This may concern individual or social ethics. Individual ethics is the critical inquiry as far as man or woman as an individual is concerned, his individual happiness and good life. Social ethics examines human action as far as man or woman as a community being is concerned.

Reflection and crticism of moral norms and values and their foundations is the area of "normative ethics". It concerns the foundations of ethics (meta-ethics), theoretical concepts and applied ethics. We can distinguish between theoretical concepts of ethics in two ways. We can look at the acting subject or at the object of the action. We can also look at the consequences (teleological ethics) of behavior or the reasons why someone does something (deontological ethics). A duty is a good character trait for good living together. A Kantian ethic of duty will answer the question of what I should do or whether my actions are lawful by appealing to freedom, which, according to Kant, is nothing but reason. That is the autonomous self-determination of the rational being: only actions that conform to the demands of pure reason are permitted. Aristotle starts from the purpose of human life, calling it "happiness" as "optimal self-realization", which is answered by the theory of virtue. This is also reflected in current value ethics and in the revival of virtue ethics, as described by Sanderse (2018). John Rawls' contractualist theory is concerned with rules of justice that justify actions within certain institutions. Within utilitarianism, the highest moral point of view consists in weighing up the costs and benefits of the expected consequences of action. Utilitarianism

\footnotetext{
${ }^{7}$ Nussbaum (1993) describes the capabilities approach. Tinnevelt and Denier (2015) describe Nussbaum's philosophy as activism.
} 
identifies happiness with general bliss. As a principle of moral good, hedonism identifies happiness with lust.

Over time, morality indicates the totality of beliefs, decisions, and actions by which people express what they think is good or proper. Greek culture was founded on ancient traditions, such as myths, where many questions of life were explained and legitimized by small groups. The collective maintained this system until reason was discovered. From the Renaissance and the Enlightenment, rational thinking has led to many new, technical developments. At the moment technology hold us even in hold. It is very important that ethics and morality are concerned with whether we are free to use technology or not. Michel Foucault (2006) saw a connection between rules, institutions and power. He became known for his research into the relationship between knowledge and power. Power arises from inequality, differences or imbalance. According to Foucault, the form of the subject is made by power. Power has a purpose. Power is used, through tactics (micro) and strategies (macro), to control knowledge. Foucault distinguishes between "savoir" (subjects are created and thus become objects of knowledge) and "connaissance" (the knowledge about these subjects). According to Foucault, there is a relationship between power, knowledge and language in which the prevailing views of knowledge are expressed. That power comes from a subtle system of rules, which are conveyed through communication. There are all kinds of institutions, such as mental health care, companies, hospitals and government agencies that watch us, so that we behave in a desired way.

\subsection{RATIONALITY}

Rationality is the movement in which consciousness is separate from the world, independent and determining. The subject (man/woman) is opposite to the object (the world), but the emphasis is on the subject and "being-self". Like Parmenides, Socrates believed that we could only acquire knowledge with the help of our ratio. Aristotle sought the source of knowledge in our perception of physical reality. There is dualism, which is not exclusive to the Western world. For example, Slingerland (2013) points out that in early Confucianism there was already a weak dualism between body and mind, as in the rituals, and we also see tendencies of dualism in neo-Confucianism.

In the west, dualism in the Middle Ages refers to the Abrahamic religions, in which man or woman consists of a physical body and an immaterial soul. Medieval philosophy was embedded in the Christian context, and intellectual thought was subordinated to theology. Scholasticism held that man may also investigate God's creation and caused a break between philosophy and theology. In the Renaissance people began to appreciate the achievements of classical antiquity again and important new developments occurred. Classical humanists, including Erasmus, put humanity at the center. Like Plato, Descartes and Leibniz believed that ratio is the source of knowledge. Descartes was the founder of the modern "I". He made a distinction between body and mind and wanted to arrive at real, absolute truths (cogito ergo sum). 
After the Renaissance, a contrast arose between rationalism and empiricism. ${ }^{8}$ Empiricism states that all knowledge is based on (sensory) experience. We are born as a blank page (tabula rasa). According to the empiricists such as John Locke, George Berkeley, Thomas Hobbes and David Hume, knowledge, like Aristotle, comes from sense perception. We learn through experiences. In the Enlightenment, people got rid of dogmatic belief in authority. As a legacy of the Enlightenment, German idealism arose around 1700 (in the work of Johann Fichte, Friedrich Schelling and Georg Hegel) with the French Revolution as its historical background. The struggle between rationalism and empiricism was arbitrated by Kant's (1975) synthesis. The "Thing in itself" is made knowable by the rationally ordered phenomena. Then reason and experience work together, and real knowledge is possible. According to Hegel, we should view everything as a historical process. He sees rationalism as the thesis and empiricism as the antithesis. Kant's philosophy is synthesis. According to Kierkegaard, the emphasis on scientific reason, as in Kant's hegemony of reason, among other things, leads to existential emptiness and greater psychological distress. During the Romantic period (19th century) subjective experience was taken as the starting point. As a result, introspection, intuition, emotion, spontaneity and imagination became central. Charles Darwin's work was based on the idea of organic self-regulation. Adam Smith also defended the view that through the self-regulating effect in the economic system of the market, the "invisible hand" would ensure maximum prosperity for all.

In contemporary philosophy as a whole, an important shift towards language took place from the beginning of the 20th century, the "linguistic turn". 9 The initiator of this development was Wittgenstein. This follows from the idea that philosophical problems arise from a misunderstanding of the logic of language in his early work, and comments on language games in his later work. Two schools of philosophy dealt with this differently. In continental philosophy much attention was paid to philosophy of language, although language was not seen as a separate discipline. See the segment Differentiality. In analytic philosophy, philosophy of language became the main focus, through research into the nature of language and the relationship between language and users. Gottlob Frege and Bertrand Russell were key figures (Russell 2006). This work was a great source of inspiration for the Vienna Circle and their logical positivism. ${ }^{10}$ Karl Popper, who came into contact with the Vienna Circle, is troubled by the fact that theories seem capable of explaining everything. His point is that a theory must be falsified. Popper (1935) thus argued against the inductive method of verification and for the deductive method of falsification.

Logical positivism can be divided into two schools of thought: (continental) phenomenalism, with correspondence as the criterion, and (analytic) physicalism, with coherence as the criterion. These schools of thought attempt to solve the mind-body

\footnotetext{
${ }^{8}$ Cf., "Rationalism vs. Emiricism", Stanford Encyclopedia of Philosophy <https://plato.stanford.edu/ entries/rationalism-empiricism/>.

${ }^{9}$ Described in detail by Rorty (1992).

10 Described in: Universität Wien. The "Vienna Circle" ("Vienna Circle") 1924-1936. https://geschichte.univie.ac.at/en/articles/vienna-circle-wiener-kreis.
} 
problem. Physicalism holds that the mind is part of the material or physical world. That tends towards a philosophical materialistic monism, in which the subject man or woman is also able to fully understand mental events as science develops. Other terms used in analytic philosophy are "pan psychism" and "expanded mind", meaning that the "self" is not located solely within the limits of the brain, but expands into the environment. The subject wants to get to know and understand material reality and goes further and further into it. Measured by participation in religious organizations, there has been recent secularization in the west. At the same time, there are more people who practice some kind of religion, but in a more individualistic way. This advance of individual religiosity goes back to Calvin, who taught, among other things, that the individual is more and more central. Prayer is present on all theistic paths (Biesta et al (2001). Prayer is an exercise to direct our minds to the divine with devotion and surrender. Singing is used in some paths as a means of prayer.

\subsection{SOCIALITY}

In Sociality humans have a great influence on the world: the object (world) is part of the subject (humans), with an emphasis on the object and on "learning-society". The importance of the object (world) is accentuated and goes so far that Marx says that the economic foundation determines man's or woman's ideology, and not, as Hegel believed, the idea determines reality. Marx reverses, as it were, the subject-object relationship in this quadrant. Subsequent developments are - dialectically - influenced by this and show as a synthesis that we have to interfere more with society, for example through the development of the social sciences.

After Socrates and Plato, little or no attention was paid to society and man- or woman's place in society for a long time. The idea of the "social contract", in which the individual and his place in the community are central, is addressed by Hobbes, Locke and Jean-Jacques Rousseau, ${ }^{11}$ after which social science, with Auguste Comte and Max Weber as founders, develops. Comte was also the founder of positivism. The social contract is about when a regime or power is legitimate. This is determined, as it were, in a kind of agreement that the individuals of a society have entered into with each other, in which it is agreed, who has the power and what that entails. The main driver of the Hobbes' social contract is fear. He emphasizes that only the state has the capacity to create basic security for all individuals. According to Locke, everyone has a duty to preserve themselves and others. Rousseau wondered why people are unequal to each other.

The history of thought is not a development along a straight line, but a development through opposites. Dialectics (the model These - Antithesis - Synthesis) was already used in classical times in the search for truth in a dialogue from opposite starting points (for example the Socratic questioning). Since Hegel and Fichte, dialectics have been used within philosophical movements about man or woman and society. Karl Marx was a student of Hegel and built on his ideas and also used dialectics as a method. World

${ }^{11}$ Social Contract Theory, Internet Encyclopedia of Philosophy. https://iep.utm.edu/soc-cont/. 
history is largely determined by economic conditions. The dominant class exploited the working class to increase its own profit. Ultimately, the power relations between the bourgeoisie and the working class must lead to a revolution.

The Frankfurt School (German: Frankfurter Schule), with main representatives such as Max Horkheimer, Theodor Adorno, Jürgen Habermas and Herbert Marcuse, focuses on the philosophical foundations of the social sciences. ${ }^{12}$ They reject Comte's positivist approach. The Frankfurt School is concerned that the sciences also actively deal with their relationship to society, with which they follow Marx. Progress also leads to culture control and legitimacy for power and violence. These drawbacks are very much linked to the Second World War. There was agreement that critical social theory was needed. The "critical theory" indicates that every scientific question must be accompanied by a critical analysis of the associated societal image. At this point we see a dichotomy in the philosophical responses: on the one hand responses that we must let go of the premise of one rationality, which led to postmodernism (see the segment Differentiality), and responses that we must nevertheless adhere to one rationality, but must continue to criticize societal developments from within. Habermas in particular has been concerned with this immanent criticism. He saw that institutions, such as politics, media and large corporations, try to influence the public sphere, leaving less room for rational debate. For example, the culture industry provides mass entertainment and mass control and ensures that people no longer think for themselves. In his theory of communicative action, he explains how to conduct this debate. He argues that in addition to classical instrumental rationality, there is also a "communicative rationality" arising from the structure of the language itself. In this view, truth comes about in a debate (consensus theory).

Thinking about freedom in a political sense can be seen in Arendt's philosophy, whose work has been influenced by Heidegger, Nietzsche, Kant, Karl Jaspers and Aristotle, among others. ${ }^{13}$ She analyses the historical (back) grounds of the totalitarian state. It deals with the freedom of the individual, concentration camps and the disappearance of the difference between fact and fiction. It was, according to Arendt, not malicious intent, but the lack of critical thinking and the uncritical following of orders from above that led so many Jews to lose their lives in the structural extermination policies of the Nazis. She systematically analyses the problem of thinking and knowing. The value of thinking is that it can give meaning to certain actions, situations and experiences. Relationships can be made with the work of Habermas, Foucault and Seyla Benhabib, among others. Rawls (2006) wants to develop a theory of justice in social relations. Laws and institutions, however efficient and well organized, must be reformed or rejected when they are unjust. His theory is again based on the theoretical model of the social contract. The basic principle is that every person has an equal claim to a fully-fledged basic package of rights and freedoms, which are compatible with the rights and freedoms of others and which the political authorities

12 De Frankfurter Schule, Wetenschapsfilosofie <https://www.uu.nl/wetfilos/bijsluiter/frankfurter schule.html>.

${ }^{13}$ Hannah Arendt. Stanford Encyclopedia of Philosophy $<$ https://plato.stanford.edu/entries/arendt/>. 
must guarantee. Rawls' political philosophy is seen as the foundation of the Third Way (synthesis between market and state). Then people will take into account the possible interests of all. Rawls' social contract theory recognizes the biological origin of our ethics. According to him, possibly through natural selection, man or woman has acquired a rational sense of "fairness" that makes him or her strive for justice. Following Nussbaum, who drew up individual core capacities, collective core capacities would also be appropriate here.

\subsection{DIFFERENTIALITY}

Differentiality is the philosophical movement in which the subject (man or woman) is separated from the object (the world), with an emphasis on the object (anti-subject) and the "being-all". In addition to ethics, where there is one morality for all people in the world, since the nineteenth century, people in the world have also been interested in an ethics in which morality differs from culture to culture. Edmund Husserl's phenomenology opposed rationalism and empiricism (experience) of Descartes and Hume in particular (Mayer 2021). For phenomenologists there is no objective reality, but it is created by our senses. Phenomenology was closely linked to hermeneutics, renewed by Hans Georg Gadamer (2014), which focused on the specifics of a situation, the meaning of an expression or experience. This situation is partly determined by the historical, social and cultural context. The linguistic turn in continental philosophy, unlike in analytic philosophy, was focused on language as part of many other areas of thought, such as existentialism, critical theory, phenomenology, structuralism, hermeneutics and deconstruction. The recognition of the importance of language as a constructive means was also due to the work of structuralism, in which, according to Ferdinand de Saussure, human behavior is determined by coercive social and cultural structures. Jacques Lacan, along with Foucault, Jacques Derrida and Lyotard, represented the anti-subject philosophy, ${ }^{14}$ which rejects the idea that the individual man can serve as the foundation for philosophical thought.

From the middle of the twentieth century, modernism turned into postmodernism. The Postmodernists did not believe that all problems could be solved by means of rationality. It started with Jean-François Lyotard, who heralded the end of the metanarratives such as socialism, communism, partly religion and liberalism, but with the exception of neo-liberalism. The rational man or woman who wants to control everything, with his trust in progress, among other things, fails to get a grip on the environmental devastation, the animals that die every day, the arms races and the hunger and misery in the third world. The alternative that Kierkegaard offers can also be found in postmodern views. Ramaker et al (2010) call Kierkegaard the postmodernist avant la lettre. Postmodernism thinks in terms of "difference", doubt and relativity. Postmodernism no longer places the subject (man or woman) at the center: "decentralization of the subject". In addition to structuralism and hermeneutics,

14 Jacques Lacan (1901-1981), Wetenschapsfilosofie <https://www.uu.nl/wetfilos/bijsluiter/ lacan.html>. 
active post-structuralism and neo-hermeneutics have also developed, among others by Paul Ricoeur, Judith Butler, Luce Irigaray, Julia Kristeva, Gilles Deleuze, Foucault and Derrida. In post-structuralism, closely related to post-modernism, it is believed that social, cultural or psychological structures strongly limit the possibilities of human action. Social constructivism says that in reality phenomena are social constructions: agreements between people.

According to Thomas Kuhn, scientists are not concerned with Popperian falsification, but with solving puzzles within a theoretical framework, where interests play a major role. Derrida took postmodernism a little further with deconstruction thinking. This is about breaking down a theory to rebuild it. Postmodern and relativist scientists also support skepticism, which relies on other forms of knowledge, such as knowledge from religions, biological knowledge, and information transmitted through generations. Postmodernists have been accused of being impenetrable, incomprehensible and confused, referring to the so-called Sokal affair about the placement of an article about a fake scientific treatise in the trend of postmodernism in a postmodern journal. Postmodernists should take this into account precisely because they use language as a tool. In differential thinking we see a development from thinking focused on identity to thinking focused on differences. Inspirations come from no longer focusing on the subject. Derrida, Irigaray and Kristeva focus the attention, among others, on the image and representation of late-modern multi-ethnic societies, 'politics of identity' of cultural minorities, sexual difference and (post) feminism. For Deleuze, difference thinking means breaking out of the rational order and doing justice to the diversity of reality. ${ }^{15}$ Deleuze refers to Hume who assumes that the subject does not have a fixed or pre-existing identity, but is a process that forms in a continuous interaction with the world around it. To Deleuze, starting from difference means not only breaking out of the rational order, but also breaking out of every order, including the social and political order. The result is chaos. Philosophy can help get out of this, not by looking for a solution to the problem, but by constantly developing the necessary implications of the question posed. The only thing left to do, is to make a start with the new politics in the hope that it will be contagious and set in motion new developments.

Dualistic Hinduism in the East continues to develop. Ideas and habits of thought of the mind hinder the attainment of true (metaphysical) knowledge and must be overcome by a higher consciousness. It leads to a better understanding of the fundamental nature of all that exists. This goes together with self-realization, the pursuit of a state of mind with more possibilities and greater freedom. The Hindu believer will find that physical pleasure and material success as a form of meaning are ultimately very limited and he or she will be open to discovering a much more important motivating force: duty. Based on an ethical way of life and through mental exercises, he or she tries to gain control over his or her thought processes, in order to discover and realize the unlimited possibilities of his or her higher self. He or she can then decide to put his or her life at the service of his or her fellow creature. By selflessly devoting him- or herself to his or her family, his or her neighborhood, his or her

${ }^{15}$ Gilles Deleuze. Stanford Encyclopedia of Philosophy $<$ https://seop.illc.uva.nl/entries/deleuze/>. 
business, his or her country, humanity, and finally the entire universe, the wisdom of 'Atma', of his or her higher self, will always make him or her see how to act.

Yoga (connection, unification) is important in the dualistic Samkhya and Dvaita Vedanta Schools. Thus the Samkhya School distinguishes the physical active prakrti (your body, your thoughts and your mind; everything you see, hear and feel) and the spiritual passive purusha (the true being). Only when it is possible to realize this distinction, the soul can become truly known and free. There are several systems: jnana yoga (direct spiritual insight through self-reflection and meditative inquiry); karmayoga (salvation through selfless and mindful action); bhakyi yoga (loving devotion and surrender to the deity, or Vishnu (or his avatar Krishna, or Shiva); raja yoga (higher spiritual faculties through mind and body control). In the west, fewer people value traditional religions. In this secularization there is a quest for spirituality. This mainly concerns postmodern spiritual seekers. From the 1960s onwards there has been a great interest in Hinduism and Hindu spirituality in the west, such as yoga.

\subsection{HUMANITY}

Humanity is the philosophical movement, in which the object (the world, society) is part of the subject (the person), with emphasis on the person and on "learning-human", i.e. learning to be a good person as part of the society. Social ethics looks at how one should strive for virtues in life that would enable one to participate positively in group relationships. With Socrates, dialectics was the method of achieving humanity in society. Confucius based his ethical system on virtues, including charity and humanity (ren). Gottfried Leibniz, who came into contact with the publications of the Jesuit mission in China, was fascinated by the Yi-Jing. Besides Confucius, Kant also sees ethics as a process. Kant (1975) develops the categorical (objective necessity of an action that is necessary in itself, without reference to any other end) imperative: "Can you also want your maxim to become a universal law?'” In Kant the inner rational potency is the substance of our autonomy. For Confucius, loving others is the substance of our autonomy.

The development of the Confucian tradition is generally divided into three periods: the formative period, neo-Confucianism and contemporary Confucianism. NeoConfucianism wanted to return to the roots of human ethics and study the Confucian classics again. Contemporary Confucianism, begun with the May 4 Movement in 1919, emerged in response to the challenge of Western values by Confucianists. This period can be divided into 4 generations. In the 1st generation, cultural conservatives turned against the trend of blaming Confucianism for China's lagging behind the modern Western world. The 2nd generation began with the "Manifesto of Chinese Culture," published January 1, 1958 by Mou Zongsam and others. Students of the 3rd generation, including Tu-Weiming, wanted to promote Confucianism as an important voice in the symphony of world cultures. According to Li Zehou, in the 4th generation, the cosmos

and human society are rooted in harmonious human relationships based on a shared sense of community. Confucianism can learn from elements of Marxism, liberalism, existentialism and post-modernism from the West. The first decade of the 21 st century 
saw a Confucian revival movement. Billioud and Thorvalo (2015) discover three trends: rediscovery of the Confucian classics; resurgence of Confucian rites and rise of religiosity; and the question of what role Confucianists can play in the future ideological reconfiguration of the country (politics). Richard Rorty, initially under the spell of logical positivism and analytic philosophy, points to the fixation of Western philosophy on the knowledge problem. ${ }^{16} \mathrm{He}$ argues that Western democracy is best served by an "unfounded" pursuit of solidarity. However, he finds no way to unite reality and justice in one theory. He continues to write on political issues, human rights and injustice and continues to call for existing class contradictions to be placed on the political agenda. All his life he has tried to contribute to a world with less poverty and hunger. Yong Huang and Rorty (2009) compile articles on an encounter between Confucianism and Rorty's philosophy. Looking at the historical development because of serious social, moral, environmental and even existential problems, Geir Sigurdsson (2014) answers the question whether Confucianism has anything to contribute to modernity in the affirmative. He sees a tension between the role of Confucianism in creating a trust-based community through self-cultivation on the one hand and the role of economic values in modern developments on the other. The modern Confucianists do not want to reject modernization, but do want to reject modernization in the Western manifestation (individualism and liberalism). We can arrive at decent responses through rituals. Experience (of rituals) was important. The assumption in Confucianism is that there are enough resources for everyone to live a decent life, and that scarcity is caused by individual greed of those in power. Confucius (2010) says: "I have heard that the ruler of the state or the head of a household does not worry that his people are poor, but that wealth is inequitably distributed. For, if wealth is equitably distributed, there is no poverty."

\section{SUMMARY AND CONCLUSIONS}

The Book of Changes, Yi-Jing, and the Diagram of Supreme Polarity inspire the formation of a model, which, from the symbolism of the duograms and trigrams, offers opportunities to discuss different philosophical movements in parallel, and thus forms a framework for development of theory and methodology of comparative philosophy. The universal basic concepts of $l i$ and $q i$ lead to a coordinate system, with energy on the horizontal axis and pattern or form on the vertical axis. This is a general system, which has similarities with Libbrecht's model of comparative philosophy, but also some differences. There are also similarities with Wilber's quadrant system. The duograms have a place in this and correspond to four traditional philosophical movements: Naturalism, Rationalism, Humanism and Moralism. By adding diagonal axes based on the tension between competition and cooperation and the tension between renewal and preservation, a coordinate system with eight octants is created, which makes it possible to discuss a further differentiation of the various philosophical traditions in parallel, which does justice to the increased philosophical diversity. This too is a general system,

${ }^{16}$ Richard Rorty, Stanford Encyclopedia of Philosophy $<$ https://plato.stanford.edu/entries/rorty/>. 
in which the trigrams have a place in an arrangement that shows both opposites and a sequence that corresponds to the sequence of the Five Phases in the production cycle: the YI-Ba-Gua. In the degrees of freedom of the trigram sequence, which first descend and rise again after a turning point, we further recognize the immanent and transcendent processes of the evolution of the cosmos. There is also a correspondence between this $Y \mathrm{I}-\mathrm{Ba}-\mathrm{Gua}$ and Spiral Dynamics.

The philosophical movements in the quadrants are characterized by, among other things, a fundamental difference in the relationship between the subject and the object. In the octants these fundamental relationships remain intact, but we see on the one hand philosophical developments that place more emphasis on the subject and on the other hand philosophical developments in which the object carries more weight, which also has consequences for the ontological representation.

Using the system of the Yi-Jing octant system, we have sketched a diverse picture of eight different movements that can be recognized in philosophy worldwide. As in the Yi-Jing model, these philosophical movements are interdependent, seemingly opposite, but complementary to each other. This approach thus contributes to the theory and methodology of comparative philosophy, especially the part of comparative philosophy that concerns extracting, analyzing and comparing common features. The other part of comparative philosophy is achieving harmony, based on the exploration of the contraries between the different philosophical movements. This is the subject of a new paper under construction.

Taking into account four adequacy conditions mentioned by Mou (2020), the YiJing cosmic model and the Hegelian model can jointly contribute to our understanding and treatment of the reflexive issue of how to look at the due relation between contraries. Since achieving harmony (harmonious balance) is only accomplished through concordant contraries as in the Yi-Jing system, whether or not through intervention of the Hegelian model or otherwise, I conclude that the Yi-Jing cosmic model can be seen as a framework for comparative philosophy.

In the philosophical movement Naturality, the subject (man or woman) is part of the object (nature), with emphasis on nature, as in Daoism and ecocentrism. The focus is on movement between Yin and Yang, and change, as Heraclitus saw it (panta rhei). Man or woman is no more valuable than other life forms; it is about "becoming all". Like Daoism, Nietzsche also wanted to free nature from violent human distortions. Spirituality helps to find inner peace and to harmonize with the Dao.

Connectivity is the philosophical movement, in which the subject (the human being) coincides with the object (the world). The emphasis is on man or woman, who strives for liberation, as in Buddhism. He or she looks for a path to internalization, the "nonbeing-all", as in parts of Hindu philosophy (Theravada and Mahayana). In parts of Western philosophy we also see a monistic worldview, in which reality consists of one substance (Spinoza) or is seen as the result of one continuous, dialectical process (Hegel). Reaching a state of enlightenment can be achieved through spirituality, meditation, yoga and Zen (Eastern philosophy) and through meditation and introspection (Heidegger). 
Existentiality is the philosophical movement, in which the subject (man or woman) is part of the object (nature or world), but man or woman puts his or her 'ego' at the center. Man or woman is looking for the "self" (Socrates) and how he or she becomes him- or herself (Kierkegaard), the "becoming-self". Kierkegaard's religious message to resolve the insoluble contradiction in our existence between contingency and freedom was pushed aside by the atheistic existentialism of Nietzsche and Sartre, among others. Nietzsche's "god is dead" led to problems of meaning, in which Sartre indicates that people themselves should give meaning to life. Nussbaum sees opportunities to discover individual values for a meaningful life for yourself.

Normativity is the philosophical movement, in which the subject (man or woman) coincides with the object (the world), but is directed towards it. As a result, norms and values increasingly come into the picture, "non-being-all". Over time, normative ethics and morals have played a major role in every philosophical movement. We already saw this in ancient China (Mohists and Legalists) and also in Greek culture (ancient traditions, myths). Even today, normative ethics and morality are important in assessing new technical and social developments, which are approaching us and which can even hold us under control.

Rationality is the philosophical movement, in which the subject (man or woman) is separate from the object (the world), but is independent and determining, the "beingself'. Knowledge acquisition takes place through ratio (Socrates) or perception (Aristotle). After the emergence of religions (physical body and immaterial soul), the renaissance turned against this (Descartes' cogito ergo sum). The contrast between rationalism and empiricism was settled by Kant's synthesis. The linguistic turn in analytic philosophy inspired logical positivism and physicalism, in which rational man or woman thinks he or she is able to fully understand all events.

Sociality is the philosophical movement, in which the object (the world, society) is part of the subject (the person), with emphasis on society. Already Socrates and Plato were concerned with the place of man or woman in society, "learning-society". Important later developments concern the "social contract" (Hobbes, Locke and Rousseau), critical theory (Frankfurt School van Horkheimer, Adorno, Habermas and Marcuse), immanent criticism (consensus theory of Habermas), thinking about freedom in a political sense (Arendt) and a theory of justice, again based on the social contract (Rawls).

Differentiality is the philosophical movement in which the subject (man or woman) is separated from the object (the world). There is an anti-subject attitude (Lacan). As a critical response to rationalism and empiricism, phenomenology (Husserl) and hermeneutics (Gadamer) focused on the specifics of a situation, on the "being-all". The linguistic turn in the continental philosophy focused on questions of identity, cultural minorities, sexual difference and (post) feminism, which in the postmodernists (started with Lyotard) turns into a difference-oriented thinking (Ricoeur, Irigaray, Kristeva, Foucault and Derrida). Deleuze wants to break out of the social and political order by starting new politics himself. Ethical lifestyles, as in parts of Hinduism, can lead to selflessness. 
Humanity is the philosophical movement, in which the object (the world, society) is part of the subject (the person), with emphasis on the person. Human learning, i.e., learning to be a good person as part of society, is already seen in Socrates (dialectic/conversation) and Confucius (ethical system based on humanity, ren). We also see this attitude in the categorical imperative (Kant). The modern Confucianists want to return to harmonious human relations (Zehou). They want modernization, but not in the Western manifestation of individualism and liberalism (Sigurdsson). Western democracy is best served by a commitment to solidarity (Rorty). Rituals can help develop decent responses.

\section{ACKNOWLEDGEMENTS}

The author thanks Antony Chang, Valérie Saintot and anonymous referees of the journal Comparative Philosophy for their stimulating and valuable comments on an earlier draft of this paper.

\section{REFERENCES}

Adler, J. A. (2015), Reconstructing the Confucian Dao, Zhu Xi's Appropriation of Zhou Dunyi (New York: State University of New York Press).

Beck, D. E. and C. C. Cowan (2006), Spiral Dynamics: Mastering Values, Leadership and Change (Blackwell Business).

Biesta, G. J. J., C. Nijnatten and S. Miedema (2001), "Education and upbringing and the return of religion in a post-modern society", Pedagogiek 21: 124-133.

Billioud, S. and J. Thorvalo (2015), The Sage and the People: The Confucian Revival in China (Oxford: Oxford University Press).

Bor J. and K. van der Leeuw (ed.) (2003), 25 Centuries of Eastern Philosophy (Amsterdam: Boom).

Brobjer, Th. H. (2004), "Nietzsche's reading about Eastern Philosophy", Journal of Nietzsche Studies 28: 3-35. https://www.jstor.org/stable/20717839.

Cacioppe, R. and M. Edwards (2005), "Seeking the holy grail of organizational development: A synthesis of integral theory, spiral dynamics, corporate transformation and action inquiry", Leadership \& Organization Development Journal 26.2: 86-105.

Cheng, Ch-Y. (2009), "Li and Qi in the Yijing: A Reconsideration of being and nonbeing in Chinese Philosophy", Journal of Chinese Philosophy, Supplement to Vol. 36: 73-100. < DOI:10.1111/j.1540-6253.2009.01554.x>

Confucius (2010), The Analects of Confucius, translation by André De Vente and Eliza Yin Har Chui (Amersfoort: De Vrije Uitgevers).

Dalen, W. van (2012), Ethics, the Basics, Moral Competences for Professionals (Groningen: Noordhoff Publishers).

Dennett, D. C. (1991), Consciousness Explained (Boston USA: Little, Brown \& Co.). 
Dijkstra, M. (2004), "Dutch philosophers look no further, What does Eastern philosophy mean to the West?" Trouw, April 23.

Dondeyne, A. (1951), "Reflections on atheistic existentialism", Tijdschrift voor Philosophie 13: 3-41.

Donkers, H. (2016), “Integral Dynamics, A new Integration of Wilber's Integral Theory and Spiral Dynamics”, International Journal of Humanities and Social Science 6.6: 86-106.

Donkers, H. (2019), "Yi-Jing Integral (YI), A New Natural and Cosmic Ba-Gua", Comparative Philosophy 10.2: 1-44. <https://doi.org/10.31979/2151-6014 (2019). 100204>

Donkers, H. (2020), "The Yi-Jing Cosmic Model: With an Application of an Alternative to Neoliberalism", Comparative Philosophy 11.2: 1-35. <https://doi. org/10.31979/2151-6014(2020).110204>

Drenthen, M. (2020) Hek, The ethics of the border between farmland and nature reserve (Gorredijk: North Book Nature).

Foucault, M. (2006), The Words and the Things, An Archeology of the Human Sciences, translation by Walter van der Star (Amsterdam: Boom).

Fromm, E. (2007), The Fear of Freedom (Utrecht: Bijleveld).

Gadamer, H. G. (2014), Truth and Method. Outlines of a philosophical hermeneutic, translation by Mark Wildschut (Nijmegen: Publisher Vantilt).

Graves, C. W. (1970), "Levels of Existence, An Open System Theory of Values", Journal of Humanistic Psychology 10.2: 131-155.

Hegel, G. W. F. (2013), Phenomenology of the Mind, translation by Willem Visser (Originally published in 1807) (Meppel, Amsterdam: Boom).

Heidegger, M. (1999), Zijn en Tijd [Being and Time], translation by Mark Wildschut (Originally published in 1927) (Nijmegen: SUN).

Herakleitos (2014), Everything flows, translation by Paul Claes (Amsterdam: Athenaeum - Polak \& Van Gennep).

Hon, T. (2010), "Zhou Dunyi's philosophy of the Supreme Polarity", in J. Makeham (ed.), Dao Comparison to Neo-Confucian Philosophy (Berlin: Springer), 1-16.

Huang, Y. and R. Rorty (2009), Rorty, Pragmatism, and Confucianism, with responses by Richard Rorty (Albany NY: Suny Press).

James T. and S. J. Bretzke (1995), "The Tao of Confucius Virtues Ethics", International Philosophical Quarterly 35: 25-41. <DOI:10.5840/ipq199535157>

Kant, I. (1975), Critique of the Power of Judgment, translation by Willem Visser (Amsterdam: Boom).

Kuis, T. (2016), De Filosofie van Spinoza en het Boeddhisme [Spinoza's Philosophy and Buddhism]. <https://www.trefpuntazie.com/filosifie-spinoza-en-buddhisme/>, retrieved on December 10, 2021.

Lao Zi, (2015), Daodejing, De Weg, De Kracht [Daodejing, The Way, The Power], translation by Hans van Pinxteren (Cothen: Jewelery ship).

Lathouwers, T., L. Ramaker and J. Bor (2010), The Courage to the Impossible, Kierkegaard and Zen (Rotterdam: Asoka B.V.). 
Libbrecht, U. m.m.v. H. Kimmerle and E. Janssens (ed.) (2016), Philosophy without borders (Antwerp/Apeldoorn: Guarantor).

Lo, J. Y., P. C. Fiss, E. Y. Rhee \& M. Kennedy (2020), "Category Viability: Balanced Levels of Coherence and Distinctiveness", Academy of Management Review 45.1. Published Online: 9 Jan $2020<$ https://doi.org/10.5465/amr.2017.0011>.

Mayer, V. (2021), Edmund Husserl, Thinking without Judgments, translation by Jos Augustus (Amsterdam: Abraxas / Zuider-Amstel).

Mou, B. (2020), "Yin-Yang and Hegelian models of How to Look at Contraries, An Overall-Complementarity-Seeking Account", in Mou 2020a: 200-220.

Mou, B. (2020a), Cross-Tradition Engagement in Philosophy, A Constructive Engagement Account (New York and London: Routledge).

Nietzsche, F. (2006), Thus spoke Zarathustra, translation by Wilfred Oranje (Amsterdam: Boom).

Nussbaum, M. (1993), "Non-relative virtues: an Aristotelian approach", in M. Nussbaum and A. Sen (eds.), The Quality of Life (Oxford: Oxford University Press), 242-70.

Popper, K. (1935), Logik der Forschung (Vienna: Julius Springer Verlag).

Quik, D. (2008), Understanding the Fundamentals of Buddhism (Amsterdam: Bruna).

Rawls, J. (2006), A Theory of Justice, translation by F. Bestebreurtje (Rotterdam: Lemniscate).

Rorty, R. M. (ed.) (1992), The Linguistic Turn, Essays in Philosophical Method (Chicago / London: The University of Chicago Press).

Russell, B. (2006), History of Western Philosophy (Utrecht / Antwerp: Servire).

Sanderse, W. (2018), "The revival of virtue ethics," in W. Sanderse and J. Kole (eds.), Character, Virtues for Professionals (Leusden: ISVW Publishers), 27-36.

Sartre, J. P. (1943), L'être et le néant: essai d'ontologie phénoménologique (Paris: Gallimard).

Sigurdsson, G. (2014), "Confucianism vs. Modernity: Expired, Incompatible or Remedial?", Asian Studies 2: 21-38.

Slingerland, E. (2013), "Body and Mind in Early China: An Integrated HumanitiesScience Approach", Journal of the American Academy of Religion 81.1: 1-50. $<$ https://doi.org/10.1093/jaarel/lfs094>

Spinoza, B. (1979), Ethics, translation by Nico van Suchtelen (Originally published in 1677) (Amsterdam: World Library).

Tan, Ch. and B. Wong (2008), "Classical traditions of education: Socrates and Confucius", in Charlene Tan (ed.), Philosophical Reflections for Educators (Boston: Massachusetts: Cengage Learning).

Tazelaar, R. S. (2012), Confucius en God: Een kritische analyse van de natuurlijke theologie van Leibniz met betrekking tot het neoconfucianisme [Confucius and God: A Critical Analysis of Leibnitz's Natural Theology in Relation to Neoconfucianism], Bachelor Thesis, Faculty of Humanities Thesis, Utrecht. Available at: $<$ http://dspace.library.uu.nl/handle/1874/250452>.

Tinnevelt R. and Y. Denier (ed.) (2015), Martha Nussbaum: philosophy as activism (Zoetermeer/Kalmthout: Klement/Pelckmans). 
Veeraiah Ch. (2015), "The pursuit of happiness: An Advaita Vedanta perspective", Conference Paper (Lisbon: Happiness and Hope) <https:/www.researchgate. net/publication/305703294_The_pursuit_of_happiness_An_Advaita_Vedanta_per spective\#fullTextFileContent>

Wilber, K. (2004), A Concise History of Everything, a Superb Synthesis of Science and Spirituality (Rotterdam: Lemniscate).

Wilhelm, R. (2016), I Tjing, The Book of Changes, with a foreword by prof. Dr. C. G. Jung (Deventer: Publisher Ankh Hermes bv).

Young, A. M. (1999), The Reflexive Universe: Evolution of Consciousness (revised edition, September 15) (Anodos Foundation).

Zhuang Zi (2011), The Complete Writings, The Great Classic Book of Taoism, translation by Kristofer Schipper (Amsterdam / Antwerp: Augustus Publishers). 